\title{
Normal levels of KIF5 but reduced KLC1 levels in both Alzheimer disease and Alzheimer disease in Down syndrome: evidence suggesting defects in anterograde transport
}

\author{
Xu-Qiao Chen*, Utpal Das, Gooho Park and William C. Mobley*
}

\begin{abstract}
Background: Impaired axonal transport may contribute to the pathogenesis of neurodegenerative diseases, including Alzheimer's disease (AD) and Down syndrome (DS). Axonal transport is a complex process in which specific motor proteins move cargoes to and from neuronal cell bodies and their processes. Inconsistent reports point to the changes in AD in the levels of the classical anterograde motor protein kinesin family member 5 (KIF5) and the primary neuronal KIF regulator kinesin light chain $1(\mathrm{KLC} 1)$, raising the possibility that anterograde transport is compromised in AD.

Methods and materials: To address inconsistencies and determine if the shared pathologies in AD and elderly DS subjects with dementia (AD in DS; AD-DS) extend to the changes in KIF5 and KLC1, we measured the levels of all the three KIF5 family members and KLC1 in the AD and AD-DS frontal cortex and AD temporal cortex and cerebellum in samples taken with a short postmortem interval. To support future studies to explore the cell biological basis for any changes detected, we also examined the levels of these proteins in the brains of young and aged adult mice in the Dp (16)1Yey/+ (Dp16) mouse model of DS and J20 mouse model of AD.

Results: There were no changes in comparison with controls in KIF5 family members in either the AD or AD-DS samples when normalized to either $\beta$-actin or glyceraldehyde-3-phosphate dehydrogenase (GAPDH). Interestingly, however, samples from control brains as well as from AD and AD-DS demonstrated strong positive correlations between the levels of KIF5 family members, suggesting positive co-regulated expression. Importantly, while earlier reports pointed to a negative correlation between the levels of the amyloid precursor protein (APP) and KIF5A levels, we found the opposite to be true in AD-DS; this was especially striking given triplication of the APP gene, with increased APP protein levels. AD and control samples showed positive correlations between fl-hAPP and KIF5 members, but they were less consistent. In contrast to the findings for KIF5, the levels of KLC1 were downregulated in the frontal cortex of both $A D$ and AD-DS brains; interestingly, this change was not seen in the AD temporal (Continued on next page)
\end{abstract}

\footnotetext{
*Correspondence: q0chen@ucsd.edu; wmobley@ucsd.edu

Department of Neurosciences, University of California San Diego, La Jolla, CA 92093, USA
}

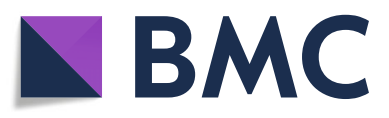

(c) The Author(s). 2021 Open Access This article is licensed under a Creative Commons Attribution 4.0 International License, which permits use, sharing, adaptation, distribution and reproduction in any medium or format, as long as you give appropriate credit to the original author(s) and the source, provide a link to the Creative Commons licence, and indicate if changes were made. The images or other third party material in this article are included in the article's Creative Commons licence, unless indicated otherwise in a credit line to the material. If material is not included in the article's Creative Commons licence and your intended use is not permitted by statutory regulation or exceeds the permitted use, you will need to obtain permission directly from the copyright holder. To view a copy of this licence, visit http://creativecommons.org/licenses/by/4.0/ The Creative Commons Public Domain Dedication waiver (http://creativecommons.org/publicdomain/zero/1.0/) applies to the data made available in this article, unless otherwise stated in a credit line to the data. 


\begin{abstract}
(Continued from previous page)
cortex or cerebellum. As postmortem interval has a negative effect on the levels of KLC1, but not KIF5 members,

we analyzed a subset of samples with a very short postmortem interval (PMI) $(\leq 6 \mathrm{~h})$, a PMl that was not

significantly correlated with the levels of KLC1 in either AD or AD-DS samples; we confirmed the presence of a

statistically significant reduction of KLC1 in AD and AD-DS brains as compared with control brains. Studies

comparing Dp16 to its euploid control recapitulated human studies in demonstrating no change in KIF5 levels and

a positive correlation between the levels of KIF5 family members. J20 mice also showed normal KIF5 levels.

However, unlike the AD and AD-DS frontal cortex, KLC1 levels were not reduced in the brains of Dp16 or J20 mice.

Conclusion: These data point to significant reductions in KLC1 in AD and AD-DS. In so doing, they raise the possibility of compromised KLC1-mediated axonal transport in these conditions, a posit that can now be pursued in model systems in which KLC1 expression is reduced.
\end{abstract}

Keywords: Alzheimer's disease, Down syndrome, Axonal transport, KIF5, APP, Dp16, KLC1

\section{Background}

The unique, polarized morphology of neurons with their long axon and multiple shorter dendrites enforces the need for accurate and efficient cargo transport to support the structure and function of both neuronal somas and their processes. Cargoes are thus moved both anterogradely and retrogradely in axons and dendrites. Anterograde cargoes are diverse and include proteins, lipids, ribonucleic acids (RNAs), and organelles; retrograde transport also engages diverse cargoes to inform somas. Among the latter are neurotrophic signals $[1,2]$. Axonal transport is mediated by motor protein complexes [3]. Kinesin family members are responsible for anterograde axonal transport; dynein and some kinesin members, including the KIFC subfamily, mediate retrograde axonal transport [3, 4]. Axonal transport defects have been linked to multiple neurodegenerative diseases $[1,2]$. Deficits in both anterograde [5-7] and retrograde axonal transport [8-12] have been extensively studied in neurological disorders including Alzheimer's disease (AD), Down syndrome (DS), Parkinson disease (PD), Huntington disease (HD), and amyotrophic lateral sclerosis (ALS). The findings have encouraged the view that axonal transport is a potential target for the development of therapeutics $[1,13]$.

$\mathrm{AD}$ is the most common cause of dementia, accounting for up to $70 \%$ of cases [14]. Clinical manifestations include memory loss, cognitive decline and behavioral dysfunction, and failure to maintain activities of daily living [15]. AD constitutes a leading cause of death with survival from diagnosis averaging 8 years for those diagnosed at age 65 [16]. The neuropathology of AD manifests in several features including amyloid plaques and neurofibrillary tangles (NFTs) [17].

DS, also known as trisomy 21, is due to trisomy for all or part of human chromosome 21 (HSA21). DS is usually associated with growth delay, intellectual disability, and distinctive facial features. In addition, those with DS have a markedly increased risk for AD [18-20].
Indeed, essentially, all adults with DS demonstrate ADlike pathology by 40 years of age, including amyloid plaques and NFTs, with dementia onset in most by age 60 [17-19], leading to the designation of this condition as $\mathrm{AD}$ in $\mathrm{DS}$ (AD-DS). The data are compelling that increased $A P P$ gene dose is necessary for AD in DS [21-23] but how increased APP levels act to advance pathogenesis remains an active area of interest. Aberrant axonal transport represents one focus, and changes in axonal transport are supported in studies in models of $\mathrm{AD}$ and $\mathrm{AD}-\mathrm{DS}$ [1, 12, 24-27]. Indeed, the evidence suggests that changes in axonal transport may significantly predate loss of synapses, axonal dysfunction, and neurodegeneration [26]. As yet unclear, however, is what role(s) in pathogenesis may be played by deficits in anterograde and retrograde transport.

Kinesin isoforms play a key role in anterograde cargo transport. Among kinesin family members, conventional Kinesin-1 is a heterotetramer consisting of two kinesin heavy chains [KHCs (kinesin family member $5 \mathrm{~s}$, KIF5s)] and two kinesin light chains (KLCs). The KHCs employ ATPase activity to generate anterograde motility; in turn, KLCs (KLC1 and KLC2) support the attachment of cargoes to the Kinesin-1 complex [4]. The KIF5 family, comprising isoforms KIF5A, KIF5B, and KIF5C, is known to mediate the anterograde delivery of APP and its processing enzymes as well as many other cargoes, including messenger ribonucleic acid (mRNA)-protein complexes, mitochondria, and neurotrophins and their receptors [4, 28-31]. KIF5A and KIF5C are exclusively expressed in neurons; in contrast, KIF5B is ubiquitously expressed. KLC1 is enriched in neurons; KLC2 is ubiquitously distributed [32, 33]. The significance of the roles played by KIF5s and KLC1 in axonal transport is supported by the phenotypes demonstrated in mice in which these genes have been deleted, including loss of motor neurons, loss of axons, motor abnormalities, abnormal accumulation of cargoes, and reduced brain size [4]. 
The gene for APP encodes a full-length APP protein (fl-APP) and its products, including transmembrane Cterminal fragments (CTFs) as well as the $A \beta$ peptides that accumulate in amyloid plaques and whose presence in toxic oligomeric species is viewed as an essential contributor to pathogenesis [17, 34]. fl-APP is processed by sequential endopeptidase cleavages. APP internalization and transport contribute to processing [35, 36]. In turn, APP products have been shown to impact axonal transport $[8,11,37-40]$. The 99 amino-acid CTF (C99) was shown to impact retrograde transport of endosomal cargoes [11, 41]; the evidence points to increased levels of C99 as also reducing anterograde transport of APP [38]. In addition, in $\mathrm{A} \beta$-treated hippocampal neurons, anterograde axonal transport of some cargoes, like mitochondria, was more affected than retrograde transport [40]. While the underlying mechanism is yet to be fully defined, these data raise the possibility that APP and its products impact axonal transport. Recent studies have addressed one possibility that is changes of motor proteins, but with conflicting findings. In one study of $\mathrm{AD}$ brain, there was an increased KIF5A mRNA level with a very small increase in the protein [42]. The finding for KIF5A protein was later challenged by a study showing marked downregulation of both KIF5A and KIF5B protein in AD [43]. Reduced levels of KIF5A and KIF5B were also detected in the 5XFAD mouse cortex and the level of KIF5A in cultures of wild-type mouse brain neurons was reduced after treating with $1 \mu \mathrm{M}$ oligomeric A $\beta 1-42$ [43]. KIF5C levels were also reported to be reduced in familial, but not sporadic, AD [44]. Somewhat more consistent findings have been reported for changes in $\mathrm{KLC} 1$ in $\mathrm{AD}$, with decreased protein levels [45-47] speculated to contribute to reduced anterograde axonal transport; nevertheless, others found no change in KLC1 [48]. In summary, existing observations with respect to $\mathrm{AD}$ are inconsistent, thus preventing a conclusion with respect to whether or not changes in KIF5 family members and KLC1 could contribute to changes in anterograde transport.

Shared neuropathological findings in AD and AD-DS motivated us to explore possible common differences relative to normal controls with respect to proteins that support anterograde transport. We examined KIF5 members and KLC1 in short postmortem interval (PMI) $\mathrm{AD}$ and $\mathrm{AD}-\mathrm{DS}$ brains and normalized to both $\beta$-actin and glyceraldehyde-3-phosphate dehydrogenase (GAPD $\mathrm{H})$. We found no change in the levels of KIF5 proteins in $\mathrm{AD}$ and $\mathrm{AD}-\mathrm{DS}$ as compared to controls. Interestingly, the levels of KIF5 family members were highly correlated with each other when examining AD, AD-DS, and controls. Moreover, positive correlations between all KIF5 members and fl-hAPP levels were consistently detected in the AD-DS group; positive correlations in $\mathrm{AD}$ were seen with all KIF5 members and fl-hAPP when normalizing to GAPDH and in controls only when normalized with $\beta$-actin. We found that KLC1 levels were significantly reduced in the frontal cortex of both $A D$ and AD-DS brains. The reduction in KLC1 was not seen in the AD temporal cortex and cerebellum. To support future studies to explore the cell biological basis for any changes detected, we also examined the levels of these proteins in the brains of a well-established model of DS, the Dp16 mouse. The Dp16 mouse provides an optimal genetic model for DS in that it harbors three copies of the $\sim 115$ mouse chromosome 16 genes homologous to human genes present on the long arm of chromosome 21 [49]. These mice have three copies of APP and demonstrate features of AD pathology [50, 51]. Like AD and AD-DS samples, the Dp16 brain showed no change in KIF5 levels nor were changes recorded in the J20 mouse model of $\mathrm{AD}$. However, unlike $\mathrm{AD}$ and $\mathrm{AD}-\mathrm{DS}$ frontal cortex, KLC1 levels were not reduced in the Dp16 or J20 brain. Taken together, these findings point to reductions in KLC1, but not KIF5 family members, in the frontal cortex of both $\mathrm{AD}$ and $\mathrm{AD}-\mathrm{DS}$ and raise the possibility that this change results in compromised anterograde transport in these disorders.

\section{Materials and methods \\ Animals}

Dp (16)1Yey/+ (Dp16) mice were obtained from the Jackson Laboratory (stock \#: 013530) and maintained by crossing females to male $(\mathrm{C} 57 \mathrm{BL} / 6 \mathrm{~J} \times \mathrm{C} 3 \mathrm{H} / \mathrm{HeJ}) \mathrm{F} 1$ mice (B6C3). Diploid (2N) littermate mice on the same background served as controls. The genotype of all animals was confirmed by polymerase chain reaction (PCR). For genotyping, tail samples were used to extract genomic DNA. A protocol was used to amplify the HPRT insertion which is only found in Dp16 mice along with amplification of the IL-2 gene as an internal control. The primer sequences used for HPRT were fwd: $5{ }^{\prime}$-AGGA TGTGATACGTGGAAGA, rev: 5'-CCAGTTTCAC TAATGACACA, while the primers for IL-2 were fwd: 5'-CTAGGCCACAGAATTGAAAGATCT, rev: 5' GTAGGTGGAAATTCTAGCATCATCC.

J20 mice were purchased from the Jackson Laboratory (B6.Cg-Zbtb20 Tg(PDGFB-APPSwInd)20Lms $/ 2$ Mmjax; Stock No: 34836-JAX) and were carried on the C57BL/6J background. APP knockout mice [52] which have been carried out on the C57BL/6J background for more than ten generations were also obtained from the Jackson Laboratory (B6.129S7-App ${ }^{t m 1 D b o} /$ J; Stock No: 004133). Genotyping of all animals was performed following the PCRbased protocol provided by the Jackson Laboratory. Wild-type mice on the C57BL/6J background served as controls for both J20 and APP knockout mice. 
All animals were maintained and bred according to standard procedures. Mice were housed 2 to 5 per cage with a 12-h light-dark cycle and ad lib access to food and water. Male mice were taken for all studies of KIF5 and KLC1 levels using sample sizes sufficient to detect statistically significant differences of $\geq 20 \%$. Sacrifice was between 7 AM and 7 PM daily; best efforts were made to minimize suffering.

\section{Plasmids and antibodies}

Rat KIF5A cDNA was cloned into pEGFP-N3 (Clontech) to create construct KIF5A-EGFP. Similarly, mouse KIF5B and KLC1 cDNAs were cloned into the pEGFP-C vector to obtain EGFP-KIF5B and EGFP-KLC1, respectively. pGFP-KIF5C was from Addgene (\#71853). Rabbit antibodies anti-KIF5A (1:2000; 21186-1-AP), KIF5B (1: 2000; 21632-1-AP), KIF5C (1:2000; 25897-1-AP), and mouse antibody anti- $\beta$-actin $(1: 10,000 ; 60008-1-\mathrm{Ig})$ were obtained from Proteintech (Rosemont, IL); rabbit antiAPP antibody (1:5000; A8717; St. Louis, MO) was purchased from MilliporeSigma; mouse anti-GFP antibody (1:2000; sc-9996) and goat anti-KLC1 antibody (1:1000; sc-13362) were from Santa Cruz Biotechnology (Dallas, TX). The mouse anti-GAPDH antibody (1:3000; GTX627408) was from GeneTex (Irvine, CA).

\section{Cell culture and transfection}

HEK293T cells were from the American Type Culture Collection (ATCC-CRL-3216; ATCC, MD) and were cultured in DMEM (10-013-CV; Corning; Corning, NY) containing 10\% fetal bovine serum (FB-02; Omega Scientific; Tarzana, CA) and $1 \%$ penicillin-streptomycin (15140122; Thermo Fisher Scientific; Waltham, MA). Transient expression was performed with polyethylenimine (408,727; MilliporeSigma) according to the manufacturer's protocol; fresh medium was supplied $4-6 \mathrm{~h}$ post-transfection. The expression of constructs was evaluated $36 \mathrm{~h}$ after transfection by Western blotting.

\section{Human sample processing}

Human AD, AD-DS, and control frontal cortexes (male and female) (AD, $n=12$, age 64-93; and control for $\mathrm{AD}$ (C/AD), $n=12$, age 48-95 (Table 1); AD-DS, $n=21$, age 41-65; and control for AD-DS (C/AD-DS), $n=19$, age 39-95 (Table 2)) and human AD temporal cortex and cerebellum (AD, $n=7$, age 64-93 and control for $\mathrm{AD}$ (C/AD), $n=8$, age 58-95 (Table 3)) were obtained from Banner Sun Health Research Institute, UCI MIND, and NIH NeuroBioBank. The AD dementia status of those with DS (AD-DS) was listed as confirmed in the samples provided by the NIH. In the cases from UCI, the diagnosis of AD-DS followed comprehensive assessments including medical history, neurological examination, and neuropsychological evaluation with particular attention given to other health co-morbidities or neuropsychiatric conditions that might cause or mimic dementia. The diagnosis of AD-DS was based upon a consensus opinion from two or more independent raters after a comprehensive evaluation of existing records and data. Participants were classified as demented if there was a history of progressive memory loss, disorientation, and functional decline over a period of at least 6 months. Samples of approximately 10 to $20 \mathrm{mg}$ frozen tissue were processed in $0.5 \mathrm{ml}$ RIPA buffer $(50 \mathrm{mM}$ Tris- $\mathrm{HCl} \mathrm{pH}$ 8.0, $150 \mathrm{mM} \mathrm{NaCl}, 1 \% \mathrm{NP}-40,1 \%$ Triton X-100, $0.1 \%$ sodium deoxycholate, $0.1 \%$ sodium dodecyl sulfate and protease inhibitor cocktail [4693124001; MilliporeSigma]) and rotated in $4{ }^{\circ} \mathrm{C}$ for $30 \mathrm{~min}$. All lysates were centrifuged $\left(12,000 \mathrm{rpm}\right.$ for $15 \mathrm{~min}$ at $\left.4{ }^{\circ} \mathrm{C}\right)$ to produce supernatants, and the protein content of supernatants was determined using the Bradford assay (5000001, BioRad, Hercules, CA). Samples were examined using Western blotting analysis.

\section{Mouse brain dissection and homogenization}

Brains were dissected using established landmarks. For Dp16 and age-matched 2N mice, the forebrain was isolated by first removing the olfactory bulbs; cerebellum and brain stem were then removed via a cut anterior to the cerebellum and extending through the posterior midbrain. Dissected forebrain was then immediately frozen in dry ice. The whole brains of J20 and APP knockout mice and age-matched wild-type mice, minus olfactory bulbs, were also dissected and frozen in dry ice. The brain, kidney, and liver were dissected from $2 \mathrm{~N}$ adult mice to evaluate antibody specificity. Brain tissues were homogenized via a Dounce homogenizer in RIPA buffer (50 mM Tris- $\mathrm{HCl} \mathrm{pH}$ 8.0, $150 \mathrm{mM} \mathrm{NaCl}, 1 \% \mathrm{NP}$ $40,0.5 \%$ sodium deoxycholate, $0.1 \%$ sodium dodecyl sulfate, and protease inhibitor cocktail) $(1 \mathrm{ml}$ for each hemibrain) and rotated at $4{ }^{\circ} \mathrm{C}$ for $30 \mathrm{~min}$. All lysates were centrifuged $\left(12,000 \mathrm{rpm}\right.$ for $15 \mathrm{~min}$ at $\left.4{ }^{\circ} \mathrm{C}\right)$ to produce supernatants, and the protein content of supernatants was measured by Bradford assay.

\section{SDS-PAGE immunoblotting}

Established protocols were followed for SDS-PAGE/immunoblotting [53]. Equal amounts of total proteins for each sample $(10-20 \mu \mathrm{g})$ were separated on SDS-PAGE and then electrotransferred to nitrocellulose membranes (Bio-Rad). The membranes were blocked with 5\% nonfat milk for $1 \mathrm{~h}$ and probed with specific primary antibodies overnight at $4{ }^{\circ} \mathrm{C}$ followed by incubation with goat antirabbit IgG-HRP $(1: 15,000 ; 111-035-144)$ or anti-mouse IgG-HRP $(1: 15,000 ; 115-035-003)$ or donkey anti-goat IgG-HRP (1:15,000; 705-035-003) (Jackson ImmunoResearch Laboratories; West Grove, PA) at room temperature for $1 \mathrm{~h}$. To control for false-positive signals, 
Table 1 Demographics, PMI, and clinical diagnosis for AD and C/AD frontal cortex samples

\begin{tabular}{|c|c|c|c|c|}
\hline Patient & Gender & Age (years) & Post-mortem interval (h) & Diagnosis \\
\hline C/AD 1 & Male & 79 & 3 & Cognitively normal \\
\hline C/AD 2 & Male & 80 & 3.5 & Cognitively normal \\
\hline C/AD 3 & Male & 93 & 3 & Cognitively normal \\
\hline C/AD 4 & Female & 58 & 3.1 & Cognitively normal \\
\hline C/AD 5 & Female & 59 & 3.1 & Cognitively normal \\
\hline C/AD 6 & Female & 95 & 2.5 & Cognitively normal \\
\hline C/AD 7 & Female & 49 & 7 & Cognitively normal \\
\hline C/AD 8 & Female & 54 & 6 & Cognitively normal \\
\hline C/AD 9 & Female & 59 & 5.9 & Cognitively normal \\
\hline C/AD 10 & Male & 48 & 6 & Cognitively normal \\
\hline C/AD 11 & Male & 57 & 16 & Cognitively normal \\
\hline C/AD 12 & Male & 58 & 9 & Cognitively normal \\
\hline Mean \pm SEM & $6 \mathrm{~F} / 6 \mathrm{M}$ & $66 \pm 5$ & $5.7 \pm 1.1$ & \\
\hline AD 1 & Male & 64 & 2.3 & $A D$ \\
\hline AD 2 & Male & 74 & 2.6 & $A D$ \\
\hline AD 3 & Male & 82 & 3 & Mixed vascular dementia \\
\hline $\mathrm{AD} 4$ & Male & 89 & 2.2 & $A D$ \\
\hline AD 5 & Female & 84 & 2.5 & $A D$ \\
\hline AD 6 & Female & 89 & 2.7 & $A D$ \\
\hline AD 7 & Female & 93 & 2.8 & $A D$ \\
\hline AD 8 & Female & 73 & 18 & $A D$ \\
\hline AD 9 & Female & 70 & 12 & $A D$ \\
\hline AD 10 & Female & 77 & 15 & $A D$ \\
\hline AD 11 & Female & 80 & 7 & $A D$ \\
\hline AD 12 & Male & 78 & 23 & $A D$ \\
\hline Mean \pm SEM & $7 F / 5 \mathrm{M}$ & $79 \pm 3$ & $7.8 \pm 2.1$ & \\
\hline
\end{tabular}

we used rabbit normal IgG (011-000-003, Jackson ImmunoResearch Laboratories) and an unrelated goat IgG (cathepsin D, sc-6486, Santa Cruz Biotechnology) at comparable working concentrations. All blots were developed using the BioRad Clarity Western ECL substrate and captured using ChemiDoc XRS + (BioRad); only blots within signals in the linear range were quantitated using the ImageLab 3.0.1 software (Bio-Rad).

\section{mRNA measurements}

Total RNA was extracted from AD-DS frontal cortexes obtained from NIH NeuroBioBank using Quick RNA Miniprep Kit (Zymo Research, USA) and equal amounts of total RNA were used for cDNA generation with iScript $^{\text {tw }}$ cDNA Synthesis Kit (Bio-Rad) following the manufacturer's instructions [8]. The primer sequences used for KIF5A were fwd: $5^{\prime}$-TTACCTGGACAAAATT CGTGACC, rev: 5'-GGTGACAGCCACATGACGAT; KIF5B: fwd: AGATCCTGCGGAACACTATTCA, rev: 5'-GCGGTTGCTGGTTTATCATTGG, while the primers for KIF5C were fwd: $5^{\prime}$-ATGTCTTCGACAGA GTGCTACC, rev: 5'-ACGCAAAAATCGTCCCGT TAT; KLC1: fwd: GTGAGGCACAGGTTATGATGG, rev: GTTCATCCCGTAGCCACTGAT, all from PrimerBank [54]. Polymerase chain reaction was for 40 cycles. Endogenous GAPDH mRNA was used as the internal control with the sequences: fwd: 5'-GCCACATCGC TCAGACACC, rev: 5'-AATCCGTTGACTCCGACC TTC. Values within the log-linear phase of the amplification curve were defined for each probe/primers set and analyzed using the $\Delta \Delta \mathrm{Ct}$ method (Applied Biosystems 7300 Real-Time PCR System).

\section{Statistics}

All data are presented as the mean \pm SEM. Statistical analyses were performed using PRISM (GraphPad Software Inc., La Jolla, CA) with a two-tailed Mann-Whitney test. Spearman's correlation was used to assess a relationship between proteins. The significance levels were ${ }^{*} P<0.05,{ }^{* *} P<0.01$, and ${ }^{* *} P<0.001$ unless stated, n.s., 
Table 2 Demographics, PMI, and clinical diagnosis for AD-DS and C/AD-DS frontal cortex samples

\begin{tabular}{|c|c|c|c|c|}
\hline Patient & Gender & Age (years) & Post-mortem interval (h) & Diagnosis \\
\hline C/AD-DS $1 *$ & Female & 95 & 2.5 & Cognitively normal \\
\hline C/AD-DS $2^{*}$ & Male & 93 & 3 & Cognitively normal \\
\hline C/AD-DS $3^{*}$ & Male & 79 & 3 & Cognitively normal \\
\hline C/AD-DS 4 & Male & 74 & 3.3 & Cognitively normal \\
\hline C/AD-DS 5* & Female & 58 & 3.1 & Cognitively normal \\
\hline C/AD-DS $6^{*}$ & Female & 49 & 7 & Cognitively normal \\
\hline C/AD-DS $7 *$ & Female & 54 & 6 & Cognitively normal \\
\hline C/AD-DS $8^{*}$ & Female & 59 & 5.9 & Cognitively normal \\
\hline C/AD-DS $9^{*}$ & Male & 48 & 6 & Cognitively normal \\
\hline C/AD-DS $10^{*}$ & Male & 57 & 16 & Cognitively normal \\
\hline C/AD-DS $11^{*}$ & Male & 58 & 9 & Cognitively normal \\
\hline C/AD-DS 12 & Female & 50 & 7 & Cognitively normal \\
\hline C/AD-DS 13 & Female & 46 & 18 & Cognitively normal \\
\hline C/AD-DS 14 & Female & 39 & 19 & Cognitively normal \\
\hline C/AD-DS 15 & Male & 59 & 5.9 & Cognitively normal \\
\hline C/AD-DS 16 & Male & 59 & 15.8 & Cognitively normal \\
\hline C/AD-DS 17 & Female & 48 & 8 & Cognitively normal \\
\hline C/AD-DS 18 & Female & 51 & 21 & Cognitively normal \\
\hline C/AD-DS 19 & Female & 57 & 7 & Cognitively normal \\
\hline Mean \pm SEM & $11 \mathrm{~F} / 8 \mathrm{M}$ & $60 \pm 3$ & $8.8 \pm 1.4$ & \\
\hline AD-DS 1 & Female & 45 & 2.7 & Trisomy 21 with $A D$ \\
\hline AD-DS 2 & Male & 46 & 6.4 & Trisomy 21 with $A D$ \\
\hline AD-DS 3 & Male & 49 & 2.2 & Trisomy 21 with $A D$ \\
\hline AD-DS 4 & Male & 55 & 4.5 & Trisomy 21 with $A D$ \\
\hline AD-DS 5 & Female & 57 & 6 & Trisomy 21 with AD \\
\hline AD-DS 6 & Female & 46 & 7 & Trisomy 21 with $A D$ \\
\hline AD-DS 7 & Male & 65 & 10 & Trisomy 21 with $A D$ \\
\hline AD-DS 8 & Male & 56 & 16 & Trisomy 21 with $A D$ \\
\hline AD-DS 9 & Male & 55 & 12 & Trisomy 21 with $A D$ \\
\hline AD-DS 10 & Male & 57 & 5 & Trisomy 21 with $A D$ \\
\hline AD-DS 11 & Female & 51 & 4 & Trisomy 21 with $A D$ \\
\hline AD-DS 12 & Male & 57 & 3 & Trisomy 21 with $A D$ \\
\hline AD-DS 13 & Male & 41 & 15 & Trisomy 21 with $A D$ \\
\hline AD-DS 14 & Male & 64 & 20 & Trisomy 21 with $A D$ \\
\hline AD-DS 15 & Male & 51 & 15.7 & Trisomy 21 with $A D$ \\
\hline AD-DS 16 & Male & 50 & 22.8 & Trisomy 21 with $A D$ \\
\hline AD-DS 17 & Female & 45 & 2.75 & Trisomy 21 with $A D$ \\
\hline AD-DS 18 & Female & 47 & 6.5 & Trisomy 21 with $A D$ \\
\hline AD-DS 19 & Female & 50 & 5 & Trisomy 21 with AD \\
\hline AD-DS 20 & Female & 52 & 4.37 & Trisomy 21 with $A D$ \\
\hline AD-DS 21 & Female & 62 & 2.42 & Trisomy 21 with $A D$ \\
\hline Mean \pm SEM & $9 \mathrm{~F} / 12 \mathrm{M}$ & $52 \pm 1$ & $8.3 \pm 1.4$ & \\
\hline
\end{tabular}

*The control samples also listed as C/AD in Table 1; these samples together with the remaining controls constituted the samples designated as C/COMB 
Table 3 Demographics, PMI, and clinical diagnosis for AD and C/AD temporal cortex and cerebellum samples

\begin{tabular}{lllll}
\hline Patient & Gender & Age (years) & Post-mortem interval (h) & Diagnosis \\
\hline C/AD 1 & Male & 74 & 3.3 & Cognitively normal \\
C/AD 2 & Male & 74 & 4.6 & Cognitively normal \\
C/AD 3 & Male & 79 & 3 & Cognitively normal \\
C/AD 4 & Male & 80 & 3.5 & Cognitively normal \\
C/AD 5 & Male & 93 & 3 & Cognitively normal \\
C/AD 6 & Female & 58 & 3.1 & Cognitively normal \\
C/AD 7 & Female & 59 & 3.1 & Cognitively normal \\
C/AD 8 & Female & 95 & 2.5 & Cognitively normal \\
Mean \pm SEM & 3F/5M & $77 \pm 5$ & $3.3 \pm 0.2$ & AD \\
AD 1 & Male & 64 & 2.3 & AD \\
AD 2 & Male & 74 & 2.6 & Mixed vascular dementia \\
AD 3 & Male & 82 & 3 & AD \\
AD 4 & Male & 89 & 2.2 & AD \\
AD 5 & Female & 84 & 2.5 & AD \\
AD 6 & Female & 89 & 2.7 & AD \\
AD 7 & Female & 93 & $2.6 \pm 0.1$ & \\
Mean \pm SEM & 3F/4M & $82 \pm 4$ & &
\end{tabular}

non-significant. Controls for the $\mathrm{AD}$ samples (C/AD) and for the AD-DS samples (C/AD-DS) extensively overlapped in age; for some analyses, they were examined as a group $(\mathrm{C} / \mathrm{COMB})$.

\section{Results}

Antibodies against the KIF5 family members detected proteins of the predicted size

To establish the validity and utility of the antibodies used herein, antibodies were first subjected to immunoblotting with brain lysates from the wild-type adult mouse (Fig. 1a). Each antibody revealed a distinct band of approximately the calculated molecular weight
(KIF5A, 117 kDa; KIF5B, 110 kDa; KIF5C, 109 kDa). No band at the expected molecular weight was detected when the same mouse brain lysates were probed with normal IgG from rabbits (Fig. 1a). The anti-KIF5A antibody recognized a band slightly larger than that detected by anti-KIF5B and anti-KIF5C antibodies; the antiKIF5B and anti-KIF5C antibodies recognized bands of about the same molecular weight (Fig. 1a) [32]. Other bands were observed, possibly reflecting non-specific binding or alternative splicing. KIF5A and KIF5C are highly expressed in the brain, as compared with other tissues, while KIF5B is ubiquitously expressed [32]. As a further test for the antibodies, we prepared lysates from

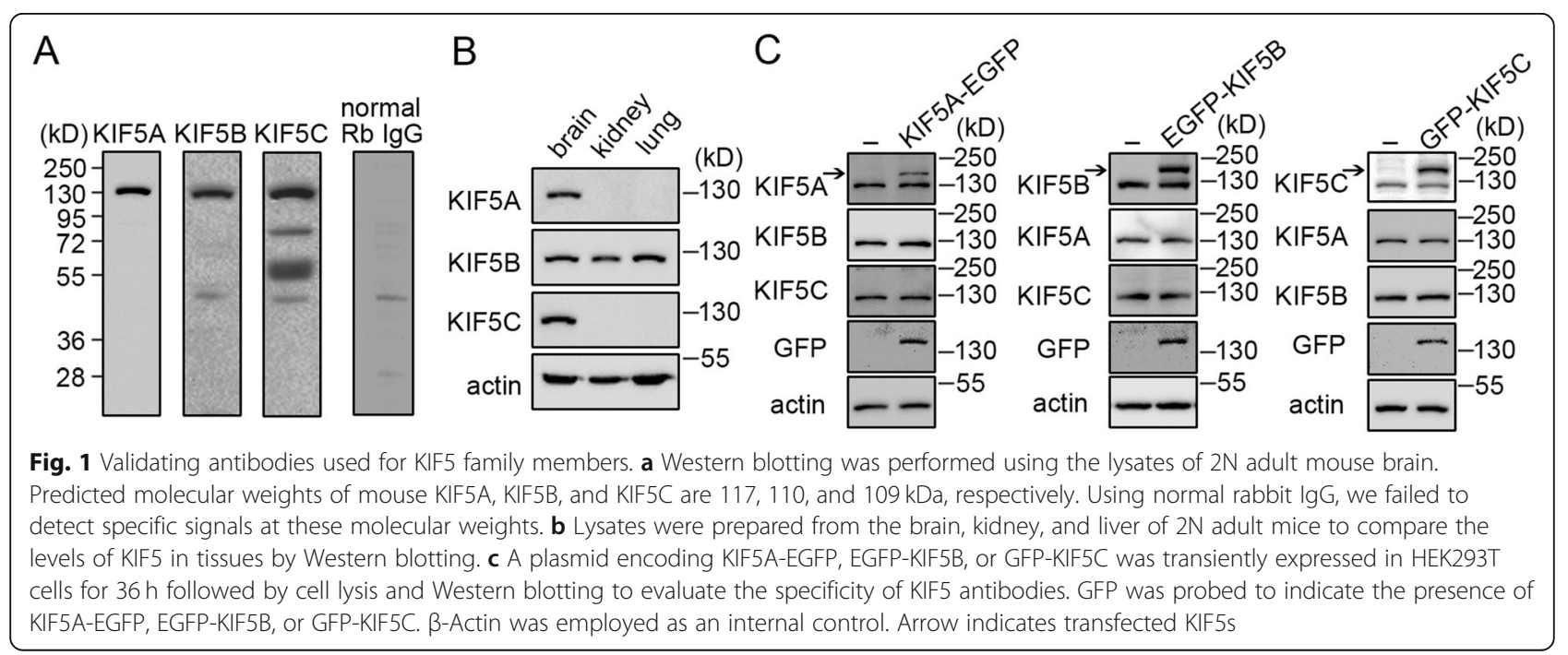


the kidney and liver of wild-type adult mice and compared the levels of KIF5 in these tissues. As predicted, both KIF5A and KIF5C antibodies detected a band only in brain samples, while KIF5B detected a band with comparable intensities in all tissues (Fig. 1b). Further evidence for antibody specificity was that in HEK293T cells, only the KIF5A antibody recognized the transfected KIF5A-EGFP, only the KIF5B antibody detected the transfected EGFP-KIF5B, and only the KIF5C antibody detected the transfected pGFP-KIF5C (Fig. 1c). These data support the use of these KIF5 antibodies to detect KIF5 members by Western blotting.

\section{Neither the levels of KIF5 family members nor APP were changed in the $A D$ brain}

Changes in KIF5A expression have been linked to AD, but with inconsistent findings [42, 43, 48]. To further examine this question, we examined the levels of KIF5 family members in postmortem $\mathrm{AD}$ brains and in ageand PMI-comparable controls (Table 1). All AD subjects were at Braak stages V-VI. To capture one brain region impacted by $\mathrm{AD}$ pathology, proteins were extracted from the frontal cortex, and the levels of KIF5 family members and full-length human APP (fl-hAPP) were evaluated after normalization to endogenous $\beta$-actin. As expected, fl-hAPP in AD samples was comparable to that in age-matched controls (i.e., C/AD) (Fig. 2a, b). While the levels for each of the KIF5 members varied across $\mathrm{C} / \mathrm{AD}$ and $\mathrm{AD}$ samples, the average level of each of the three KIF5 family members was no different in $\mathrm{AD}$ from $\mathrm{C} / \mathrm{AD}$ (Fig. 2a, c). Interestingly, the levels of KIF5 family members were strongly correlated with one another when the values for the $\mathrm{AD}$ and $\mathrm{C} / \mathrm{AD}$ cases were combined, suggesting coregulation (Fig. 2d). Separating $\mathrm{AD}$ and $\mathrm{C} / \mathrm{AD}$, a comparable positive correlation of KIF5 members was seen except between KIF5A and KIF5B in AD and between KIF5B and KIF5C in C/AD (Table 4). Finally, neither gender nor age had a demonstrable effect on the levels of KIF5 family members (Fig. 2e, f).

To confirm our findings, we alternatively normalized the levels of KIF5 members to GAPDH, another oftenused loading control. As with the $\beta$-actin control, the level of fl-hAPP did not distinguish AD from C/AD, nor did the levels of KIF5 members differ. Also, the levels of KIF5 members were significantly correlated with each other in the $\mathrm{AD}$ plus $\mathrm{C} / \mathrm{AD}$ samples (Supplemental Figure 1A-D; Table 5); separately, the $\mathrm{AD}$ and the $\mathrm{C} / \mathrm{AD}$ also demonstrated this correlation except for only a trend to significance between KIF5B and KIF5C in C/ $\mathrm{AD}$ (Table 5 ). To more widely sample the $\mathrm{AD}$ brain, we processed the AD temporal cortex, another diseaseinvolved region, and the cerebellum (Table 3). As for the frontal cortex, the levels of KIF5 members were not different from $\mathrm{C} / \mathrm{AD}$ controls in either the temporal cortex or the cerebellum (Supplemental Figure 2A-E, G$\mathrm{K})$. In the temporal cortex, the levels of KIF5 members in the $\mathrm{AD}$ plus $\mathrm{C} / \mathrm{AD}$ samples were significantly correlated with each other (Supplemental Table 1); however, in the C/AD, only KIF5A and KIF5C were correlated; in AD samples only KIF5B and KIF5C were correlated (Supplemental Table 1). In the cerebellum, positive correlations were detected in the combined $A D$ and $C /$ $\mathrm{AD}, \mathrm{AD}$ alone, and $\mathrm{C} / \mathrm{AD}$ alone. We note the possibility that a limited number of samples of these regions may have compromised the ability to demonstrate correlations in the separate $\mathrm{AD}$ and $\mathrm{C} / \mathrm{AD}$ groups in the temporal cortex. Taken together, the findings are evidence against a change in KIF5 protein levels in AD. Moreover, co-regulation of KIF5 members in the frontal cortex is supported.

\section{KIF5 levels were not changed in the AD-DS brain}

The sharing of pathological hallmarks for $\mathrm{AD}$ and $\mathrm{AD}$ DS prompted the evaluation of KIF5 members in the AD-DS brain (Fig. 3). As above, proteins were extracted from the frontal cortex of AD-DS and controls for ADDS (C/AD-DS) and KIF5 family members, and fl-hAPP levels were evaluated by Western blotting (Table 2). Consistent with the fact that the majority of adults with DS show the increased expression of the APP gene with increases in the levels of fl-APP $[18,19,21]$, and as previously reported $[55,56]$, we detected a significant increase in fl-hAPP normalized to $\beta$-actin in AD-DS brains relative to that in C/AD-DS (Fig. 3a, b). The average increase approximated that expected on the basis of increased gene dose. As for AD, the levels of KIF5 members normalized to $\beta$-actin in AD-DS subjects were not significantly different from the C/AD-DS controls (Fig. 3a, c). Also, in the combined AD-DS and C/ AD-DS samples, the levels of KIF5 family members were strongly correlated with one another (Fig. 3d). The ADDS samples alone demonstrated the positive correlation among KIF5 members; the C/AD-DS sample alone also showed the correlation except for KIF5A with KIF5B (Table 6). When we examined $\mathrm{C} / \mathrm{COMB}$, a sample containing all the controls, all KIF5 members were correlated and the significance of the correlations was increased, pointing to the benefit of increasing sample number (Table 6) and justifying the use of the C/COMB for the studies reported below. Normalizing to GAPDH, there was also a significant increase in fl-hAPP and no change in KIF5 family members in AD-DS, and the same results were obtained examining KIF5 correlations (Supplemental Figure 1E-H; Table 7). Finally, the levels of KIF5 family members were not a function of either gender (Fig. 3e) or age (Fig. 3f) for either AD-DS or C/ AD-DS. In demonstrating normal KIF5 member levels 


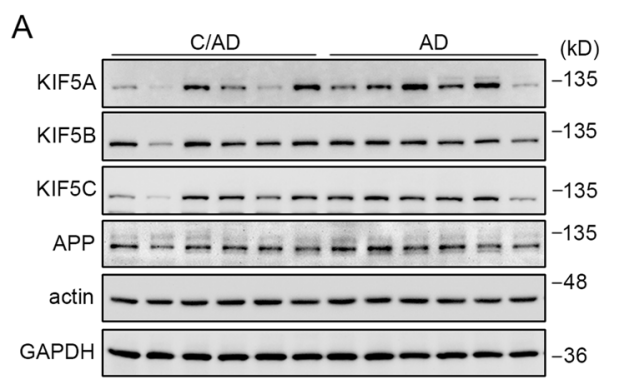

\section{B}
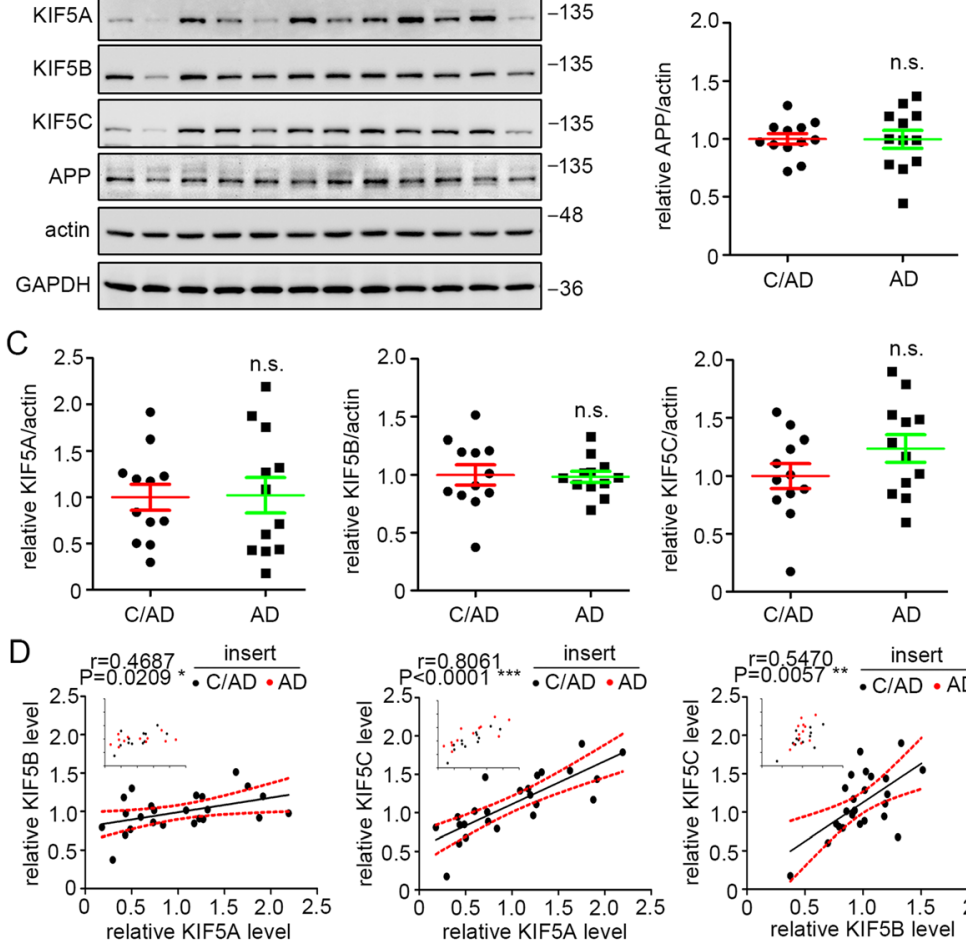

$E$
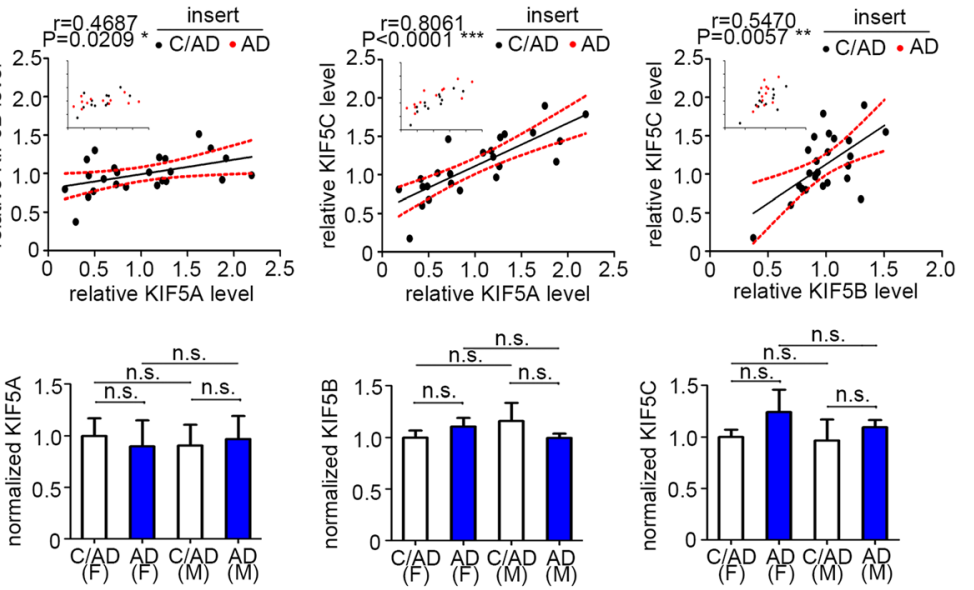

$\mathrm{F}$

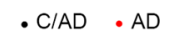
$r=-0.03509 \quad r=-0.1646$
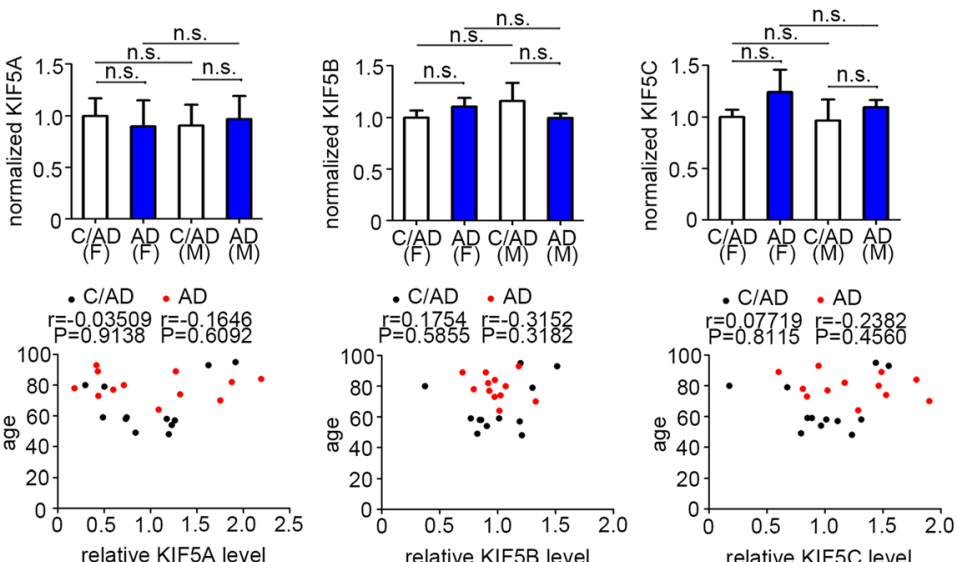

Fig. 2 Neither the levels of KIF5 family members nor APP were changed in the frontal cortex of AD brain. a Western blotting of KIF5 levels in protein extracts from the frontal cortex of patients with AD and C/AD. fl-hAPP was also probed. $\beta$-Actin and GAPDH were each used as loading controls. $\mathbf{b}$ Quantitation and statistical analysis of the levels of fl-hAPP in AD and C/AD. c Quantitation and statistical analysis of the levels of KIF5 family members in AD and C/AD. d Spearman's correlation analysis of KIF5 members in combined C/AD and AD samples; the red dotted lines mark the 95\% confidence interval. Insert with the same diagram indicates the distribution of C/AD and AD samples. e Quantitation and statistical analysis of the levels of KIF5 family members in females and males from AD and C/AD samples. $\mathbf{f}$ Spearman's correlation analyses for age and the levels of KIF5 members in $A D$ and C/AD. $n=12$ for both C/AD and AD patients; Mann-Whitney test in $\mathbf{b}$, $\mathbf{c}$, and e. n.s., non-significant; F, female; $M$, male

and their correlated expression, our findings draw additional molecular parallels between AD and AD-DS.

We were intrigued by the positive correlations between the levels of KIF5 family members in the AD and AD-DS brains. To further explore this topic, we asked if the same correlations could be demonstrated at the level of the mRNAs for these proteins. For these studies, we elected to measure the mRNA levels of KIF5 family members in randomly selected samples (4 C/ADDS and 5 AD-DS) (Supplemental Table 2). Individual samples demonstrated roughly comparable relative levels of the mRNAs for each of the KIF5 members (Supplemental Figure $3 \mathrm{~A}$ ), and there were significant positive correlations for family members with a trend to significance between KIF5B and KIF5C across the full sample set (Supplemental Figure 3B). These findings add 
Table 4 Spearman's correlation analysis between KIF5 members when normalized to $\beta$-actin in human AD frontal cortex samples

\begin{tabular}{|c|c|c|c|c|c|}
\hline Sample type & & & Sample size $(n)$ & Correlation coefficient $(r)$ & Significance $(P)$ \\
\hline$\overline{A D}$ & KIF5A & KIF5B & 12 & 0.2657 & 0.4038 \\
\hline$A D$ & KIF5A & KIF5C & 12 & 0.8392 & $0.0006^{* * *}$ \\
\hline$A D$ & KIF5B & KIF5C & 12 & 0.5804 & $0.0479^{*}$ \\
\hline$C / A D$ & KIF5A & KIF5B & 12 & 0.6014 & $0.0386^{*}$ \\
\hline$C / A D$ & $\mathrm{KIF} 5 \mathrm{~A}$ & KIF5C & 12 & 0.8322 & $0.0008^{* * *}$ \\
\hline$C / A D$ & KIF5B & KIF5C & 12 & 0.5315 & 0.0754 \\
\hline
\end{tabular}

additional support for possible co-regulation of KIF5 family members and suggest that regulatory events may act at the level of transcription and/or the stability of KIF5 mRNAs.

\section{Examining correlations between fl-hAPP and KIF5 in AD and AD-DS}

An earlier report indicated that APP levels were inversely correlated with KIF5A protein levels in AD [48]. Given that KIF5 levels were not reduced in AD samples in our study, we elected to reevaluate this issue. Normalizing to $\beta$-actin when the $A D$ and $C / A D$ samples were taken together, we observed a positive correlation between fl-hAPP levels and two of the KIF5 members (KIF5A and KIF5B) with a trend in KIF5C (Supplemental Table 3A). Separately examining AD cases, we found that the correlation between fl-hAPP and KIF5C was unchanged but that those with KIF5A and KIF5B were absent. We then performed the same analysis after normalizing for GAPDH; combining the $\mathrm{AD}$ and $\mathrm{C} / \mathrm{AD}$ samples showed significant correlations between fl-hAPP and each KIF5 member (Supplemental Table 3B). Separating the $\mathrm{AD}$ cases, the positive correlations persisted and indeed were stronger than when normalizing to $\beta$ actin (Supplemental Table 3B). When normalizing to $\beta$ actin, all KIF5 members were highly correlated with flhAPP in C/COMB; when normalized with GAPDH, the $\mathrm{C} / \mathrm{COMB}$ showed a correlation for KIF5A and a trend for KIF5C (Supplemental Table 3A, B). Examining the
AD-DS samples and normalizing to $\beta$-actin, the AD-DS and $\mathrm{C} / \mathrm{AD}-\mathrm{DS}$ samples taken together showed a trend to a positive correlation between fl-APP and KIF5B and KIF5C (Supplemental Table 4A). Independently examining AD-DS, fl-hAPP was significantly positively correlated with all KIF5 members when normalizing with $\beta$ actin (Supplemental Table 4A); fl-hAPP was also significantly correlated with KIF5 members in AD-DS when normalizing with GAPDH (Supplemental Table 4B).

Taken together, these data are evidence of correlations between fl-hAPP and KIF5 members in AD, AD-DS, and controls. These findings raise the possibility that mechanisms exist that links KIF5 and flAPP. Additional studies will be needed to confirm and more fully explore this link.

\section{KIF5 family members were unchanged in the brains of young and aged Dp16 mice}

The Dp16 mouse model of DS enables studies to explore the molecular and cellular mechanisms induced by the presence of an extra copy of many of the mouse genes whose human homologs are present on chromosome 21 . To ask if this model replicated the finding that KIF5 family members are unchanged in AD-DS, we prepared brain lysates for Western blotting from Dp16 mice and its euploid $(2 \mathrm{~N})$ controls; the forebrains only were examined, excluding the olfactory bulb and cerebellum. At age 4 months, as expected given the increase in mouse $A p p$ gene dose, an increase in

Table 5 Spearman's correlation analysis between KIF5 members when normalized to GAPDH in human AD frontal cortex samples

\begin{tabular}{|c|c|c|c|c|c|}
\hline Sample type & & & Sample size $(n)$ & Correlation coefficient $(r)$ & Significance $(P)$ \\
\hline$C / A D$ and $A D$ & KIF5A & KIF5B & 24 & 0.6113 & $0.0015^{* *}$ \\
\hline$C / A D$ and $A D$ & $\mathrm{KIF} 5 \mathrm{~A}$ & $\mathrm{KIF5C}$ & 24 & 0.8991 & $<0.0001^{* * *}$ \\
\hline$C / A D$ and $A D$ & KIF5B & KIF5C & 24 & 0.6252 & $0.0011^{* *}$ \\
\hline$A D$ & KIF5A & KIF5B & 12 & 0.6084 & $0.0358^{*}$ \\
\hline$A D$ & KIF5A & $\mathrm{KIF5C}$ & 12 & 0.8462 & $0.0005^{* * *}$ \\
\hline$A D$ & KIF5B & $\mathrm{KIF5C}$ & 12 & 0.7413 & $0.0058^{* *}$ \\
\hline$C / A D$ & $\mathrm{KIF} 5 \mathrm{~A}$ & KIF5B & 12 & 0.6713 & $0.0168^{*}$ \\
\hline$C / A D$ & KIF5A & $\mathrm{KIF5C}$ & 12 & 0.9301 & $<0.0001^{* * *}$ \\
\hline$C / A D$ & KIF5B & $\mathrm{KIF} 5 \mathrm{C}$ & 12 & 0.5455 & 0.0666 \\
\hline
\end{tabular}



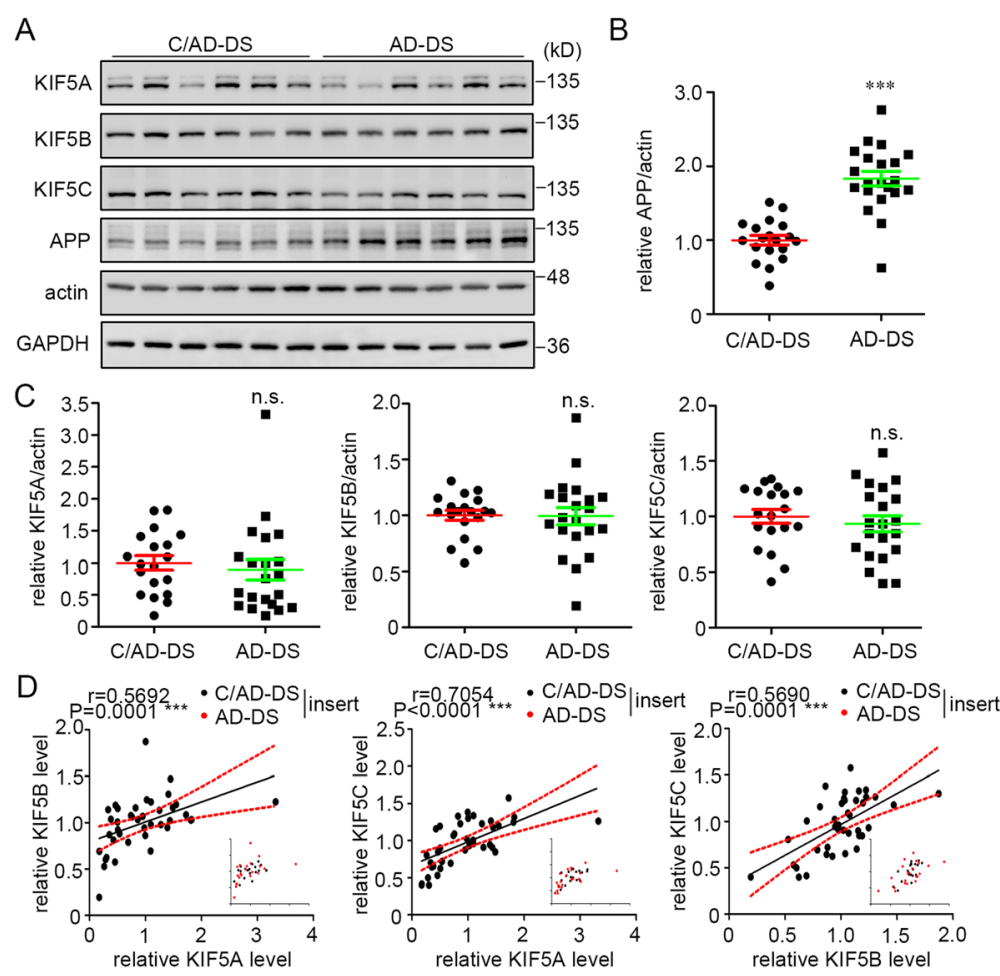

$\mathrm{E}$
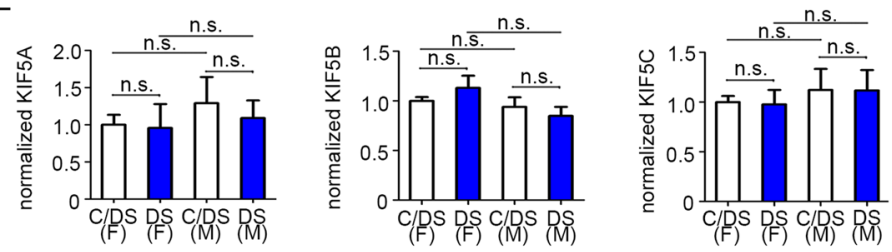

$\mathrm{F}$
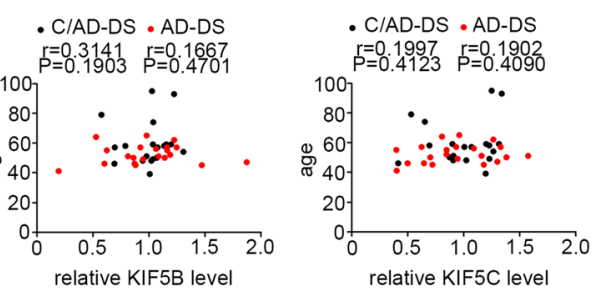

Fig. 3 KIF5 levels were not changed in the frontal cortex of AD-DS brain. a Western blotting analysis of KIF5 levels in protein extracts from the frontal cortex of patients with AD-DS and C/AD-DS. fl-hAPP was also probed. $\beta$-Actin and GAPDH were each used as internal loading controls. $\mathbf{b}$ Quantitation and statistical analysis of the levels of fl-hAPP in AD-DS and C/AD-DS. c Quantitation and statistical analysis of the levels of KIF5 family members in AD-DS and C/AD-DS. $\mathbf{d}$ Spearman's correlation analysis of KIF5 members in the combined C/AD-DS and AD-DS samples, with the red dotted line marking the $95 \%$ confidence interval. Insert with the same diagram indicates the distribution of C/AD-DS and AD-DS samples. e Quantitation and statistical analysis of the levels of KIF5 family members in females and males from AD-DS (DS) and C/AD-DS (C/DS). $\mathbf{f}$ Spearman's correlation analysis between age and the levels of KIF5 members in AD-DS and C/AD-DS. $n=19$ and 21 for C/AD-DS and AD-DS patients, respectively, Mann-Whitney test in $\mathbf{b}$, $\mathbf{c}$, and $\mathbf{e}$. ${ }^{* *} P<0.001$ unless stated. n.S., non-significant; F, female; M, male

full-length mouse APP (fl-mAPP) was detected. Consistent with the study of AD-DS samples, we failed to find the differences for KIF5 family members (Fig. 4a). As with the human samples, in the combined $2 \mathrm{~N}$ and Dp16 samples, KIF5 members were positively correlated with one another (Fig. 4b). Because, like the Ts65Dn mouse model of DS [37,
57], Dp16 mice display age-related neuropathology ([50, 58] and WCM, unpublished data), we asked if there would be age-related changes in KIF5 levels by examining the levels of KIF5 family members in aged Dp16 mice (16 months). As with younger mice, flmAPP levels were increased in Dp16 mice; again, there was no difference for KIF5A, KIF5B, and 
Table 6 Spearman's correlation analysis between KIF5 members when normalized to $\beta$-actin in human AD-DS frontal cortex samples

\begin{tabular}{|c|c|c|c|c|c|}
\hline Sample type & & & Sample size $(n)$ & Correlation coefficient $(r)$ & Significance $(P)$ \\
\hline AD-DS & $\mathrm{KIF} 5 \mathrm{~A}$ & KIF5B & 21 & 0.7143 & $0.0003^{* * *}$ \\
\hline AD-DS & KIF5A & $\mathrm{KIF5C}$ & 21 & 0.6059 & $0.0036^{* *}$ \\
\hline AD-DS & KIF5B & KIF5C & 21 & 0.6057 & $0.0036^{* *}$ \\
\hline C/AD-DS & $\mathrm{KIF} 5 \mathrm{~A}$ & KIF5B & 19 & 0.3632 & 0.1265 \\
\hline C/AD-DS & KIF5A & $\mathrm{KIF5C}$ & 19 & 0.6947 & $0.0010^{* * *}$ \\
\hline C/AD-DS & KIF5B & $\mathrm{KIF5C}$ & 19 & 0.5684 & $0.0111^{*}$ \\
\hline $\mathrm{C} / \mathrm{COMB}$ & KIF5A & KIF5B & 21 & 0.5013 & $0.0206^{*}$ \\
\hline $\mathrm{C} / \mathrm{COMB}$ & KIF5A & $\mathrm{KIF5C}$ & 21 & 0.7688 & $<0.0001^{* * *}$ \\
\hline C/COMB & KIF5B & KIF5C & 21 & 0.6584 & $0.0012^{* *}$ \\
\hline
\end{tabular}

KIF5C in comparison with age-matched $2 \mathrm{~N}$ mice (Fig. 4c). Finally, we asked if the correlations between KIF5 members and fl-APP were replicated in the mouse. We discovered no correlations between these measures in either $2 \mathrm{~N}$ and Dp16 (Supplemental Table 5). We conclude that while mice share with humans with DS the absence of changes in KIF5 levels and possible coordinate regulation of KIF5 members, they fail to show a correlation between fl-mAPP and KIF5 levels.

\section{KIF5 levels are not changed by either APP OE or KO in mouse brains}

In view of an interest in defining a mouse model system that allows one to either refute or confirm the lack of changes in KIF5 in the setting of $A \beta$ linked amyloid pathology, we analyzed KIF5 in the brains of J20 mice. The latter is a well-established AD model in which overexpression (OE) of human APP carrying the Swedish and Indiana mutations [59] results in amyloid plaques and other AD- relevant pathology by age 6 months [59-62]. We extracted total protein from the whole brains of age-matched controls and J20 mice at 6 months. Relevant to an earlier report focused on $A \beta$ effects on anterograde transport [43], J20 mice produce relatively more $A \beta 42$ than mice expressing comparable amounts of wild-type human APP [59]. As in our human samples, we found no difference between J20 and age-matched wild-type mice in any KIF5 member (Fig. 5a). Finally, to exclude any impact of APP gene expression on KIF5 levels, we examined KIF5 levels in the brains of APP knockout (KO) mice at age 12 months. Again, no alteration of KIF5 members was detected, as compared with the age-matched wild-type mouse (Fig. 5b). We conclude that KIF5 levels are not impacted in a mouse brain in which $A \beta$ levels are increased, even if amyloid plaques are present. These findings point to the conservation of control levels of KIF5 in humans with $\mathrm{AD}$ and $\mathrm{AD}-\mathrm{DS}$ and in corresponding mouse models.

Table 7 Spearman's correlation analysis between KIF5 members when normalized to GAPDH in human AD-DS frontal cortex samples

\begin{tabular}{|c|c|c|c|c|c|}
\hline \multicolumn{3}{|l|}{ Sample type } & \multirow{2}{*}{$\begin{array}{l}\text { Sample size }(\boldsymbol{n}) \\
40\end{array}$} & \multirow{2}{*}{$\begin{array}{l}\text { Correlation coefficient }(\boldsymbol{r}) \\
0.4850\end{array}$} & \multirow{2}{*}{$\frac{\text { Significance }(P)}{0.0015^{* *}}$} \\
\hline C/AD-DS and AD-DS & KIF5A & KIF5B & & & \\
\hline C/AD-DS and AD-DS & KIF5A & $\mathrm{KIF} 5 \mathrm{C}$ & 40 & 0.6572 & $<0.0001^{* * *}$ \\
\hline C/AD-DS and AD-DS & KIF5B & $\mathrm{KIF} 5 \mathrm{C}$ & 40 & 0.6225 & $<0.0001^{* * *}$ \\
\hline AD-DS & KIF5A & $\mathrm{KIF} 5 \mathrm{~B}$ & 21 & 0.6301 & $0.0029^{* *}$ \\
\hline AD-DS & KIF5A & $\mathrm{KIF} 5 \mathrm{C}$ & 21 & 0.8150 & $<0.0001^{* * *}$ \\
\hline AD-DS & KIF5B & $\mathrm{KIF} 5 \mathrm{C}$ & 21 & 0.6992 & $0.0006^{* * *}$ \\
\hline C/AD-DS & KIF5A & $\mathrm{KIF} 5 \mathrm{~B}$ & 19 & 0.2965 & 0.2177 \\
\hline C/AD-DS & KIF5A & $\mathrm{KIF} 5 \mathrm{C}$ & 19 & 0.4825 & $0.0364^{*}$ \\
\hline C/AD-DS & KIF5B & $\mathrm{KIF} 5 \mathrm{C}$ & 19 & 0.4789 & $0.0380^{*}$ \\
\hline $\mathrm{C} / \mathrm{COMB}$ & KIF5A & $\mathrm{KIF} 5 \mathrm{~B}$ & 21 & 0.4805 & $0.0236^{*}$ \\
\hline $\mathrm{C} / \mathrm{COMB}$ & KIF5A & $\mathrm{KIF} 5 \mathrm{C}$ & 21 & 0.5088 & $0.0156^{*}$ \\
\hline C/COMB & KIF5B & $\mathrm{KIF} 5 \mathrm{C}$ & 21 & 0.5178 & $0.0136^{*}$ \\
\hline
\end{tabular}




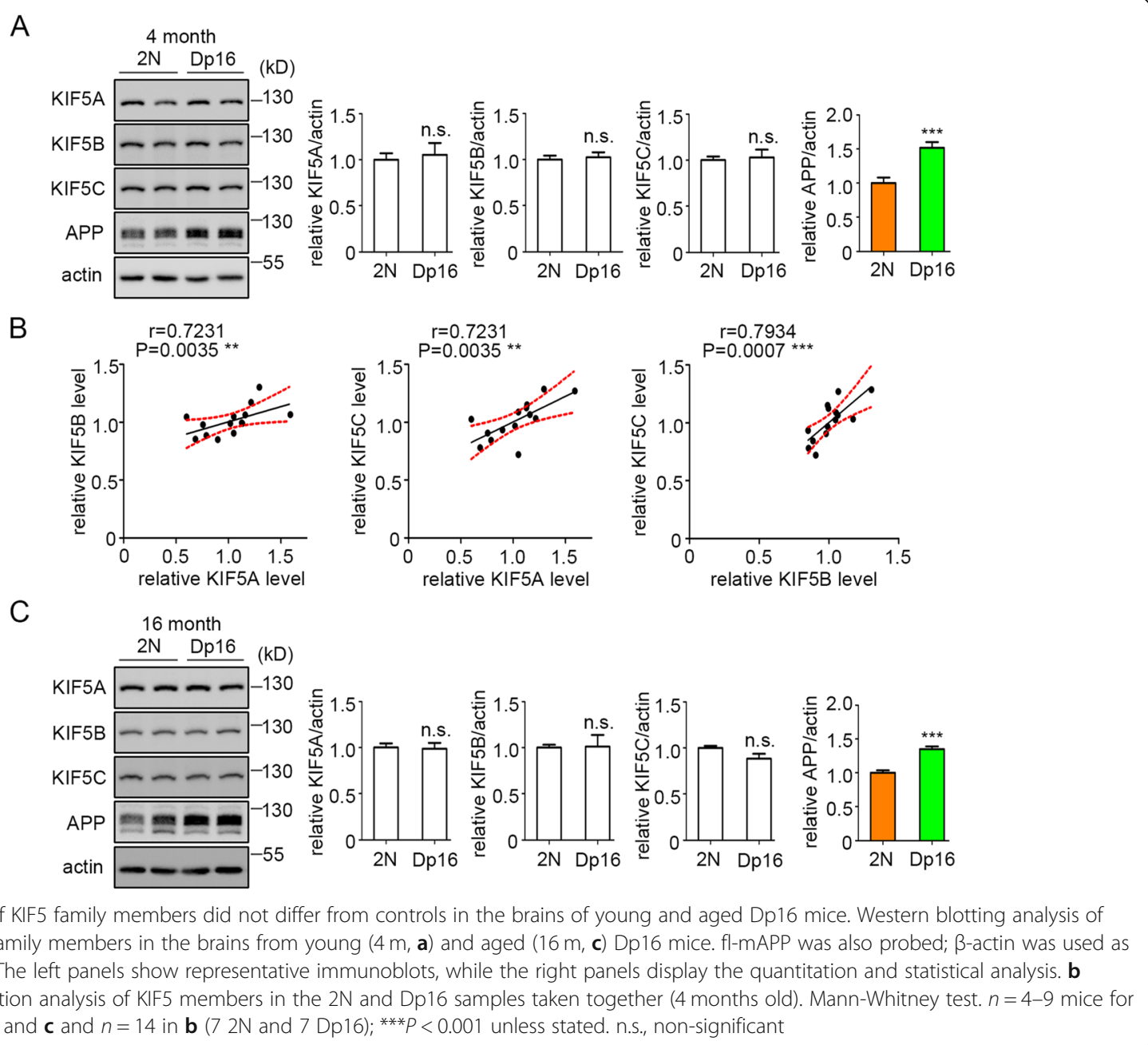

KLC1 was reduced in both $A D$ and AD-DS brains but not in the Dp16 and J20 mice

KLC1 is essential for anterograde transport of many cargoes and was reported to be downregulated in some, but not all, studies of AD [45-48]. To further explore possible shared molecular changes in AD and AD-DS, we measured KLC1 levels. The KLC1 is enriched in neuronal tissue [33]. KLC has several isoforms with molecular weight varying from 51 to $76 \mathrm{kD}$ [63]. First, we confirmed the specificity of the KLC1 antibody by probing blots of the lysates of HEK293T cells transfected with EGFP-KLC1. A band corresponding to the molecular weight of the fusion protein was only present in the lysates of transfected cells (Fig. 6Aa). A major band detected by the KLC1 antibody was found at approximately the calculated molecular weight $(65-70 \mathrm{kD})$ in mouse brain lysate. No signal was detected using a goat IgG antibody to an unrelated antigen (cathepsin D)(Fig. 6Ab).

In human brain samples, bands at apparent molecular weights of between 63 and $75 \mathrm{kD}$ were detected and were quantitated together. In AD samples, as compared with age-matched controls, we found a significant $\sim 50 \%$ reduction in KLC1 levels when normalized to $\beta$-actin (Fig. 6B, C). Reduced KLC1 was seen in both AD females and males (Fig. 6D). The change in the levels of KLC1 in the frontal cortex of AD was confirmed when the levels of KLC1 were normalized to GAPDH (Fig. 6B; Supplemental Figure 1I). Interestingly, in the AD temporal cortex and cerebellum tissues, we failed to find a reduction in KLC1, as compared with C/AD (Supplemental Figure 2A, F, G and L), pointing to a regionspecific change in the levels of KLC1. The finding in the AD cerebellum is consistent with a prior report [47]. KLC1 levels were also decreased in AD-DS, with an average reduction of $\sim 40 \%$ when normalized to either $\beta$-actin or GAPDH (Fig. 6E, F; Supplemental Figure 1J). There was no significant effect of gender on the levels of $\mathrm{KLC}$ in C/AD-DS or in AD-DS samples (Fig. 6G). Importantly, we found a significant negative correlation between PMI and KLC1 in AD and AD-DS brains, but 


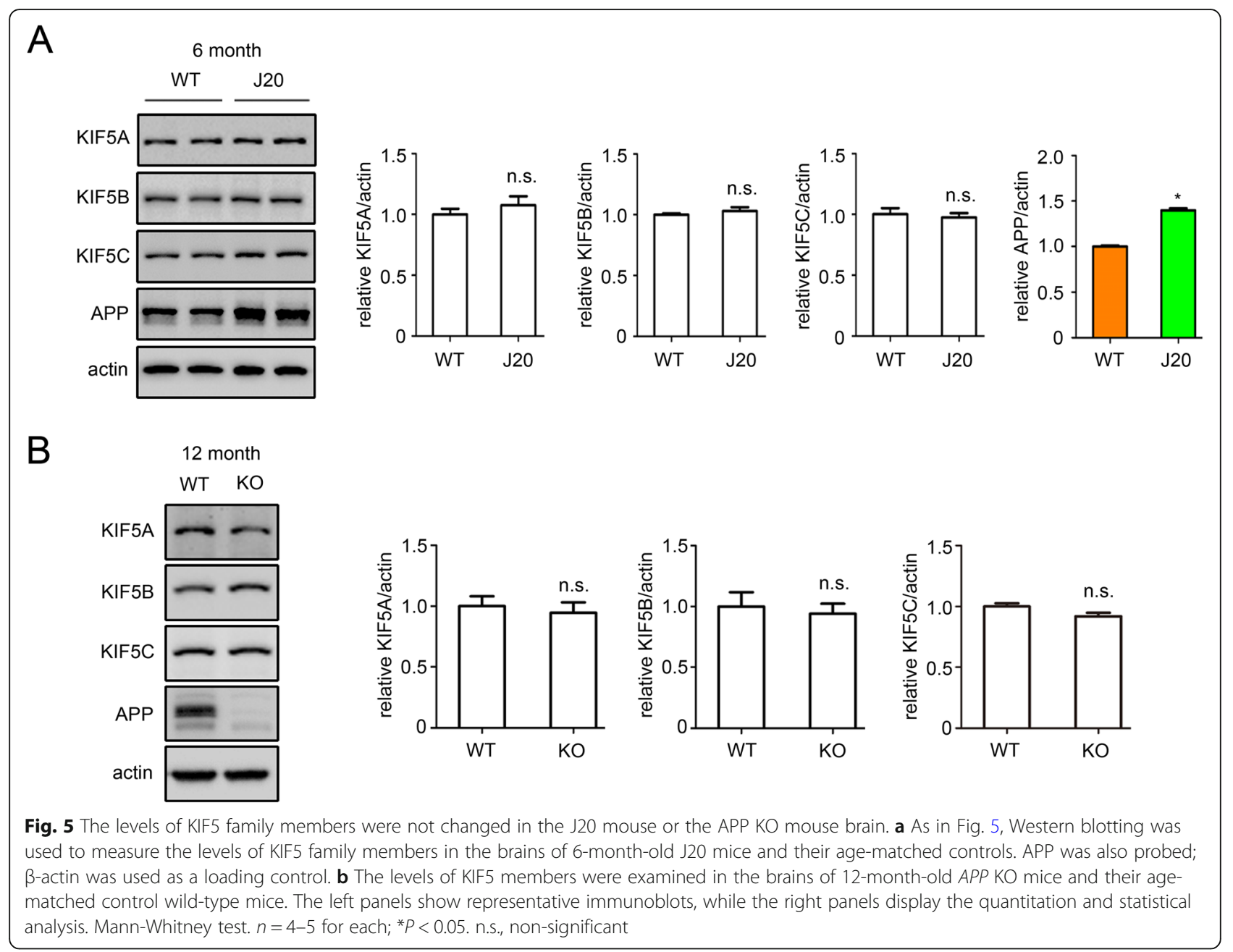

not in control brains (Supplemental Table 6). We then analyzed a subset of samples with a very short PMI $(\leq 6$ $h)$; under this condition, PMI was not significantly correlated with the levels of KLC1 in either $\mathrm{AD}(r=-0.2060$; $P=0.7139)$ or AD-DS $(r=-0.5786 ; P=0.0622)$ samples. In these very short PMI samples, KLC1 was again significantly reduced in both $\mathrm{AD}$ and $\mathrm{AD}-\mathrm{DS}$ brains compared with control brains (Supplemental Figure 4). Pointing again to the differences between human samples and those in mouse models, we failed to find a difference in the levels of KLC1; KLC1 levels were equivalent to control values in both the Dp16 and J20 brains (Fig. 6H-J). We conclude that KLC1 levels are reduced in both males and females with $\mathrm{AD}$ and $\mathrm{AD}-\mathrm{DS}$.

The reduction of KLC1 protein in AD-DS raised the question as to whether this change was solely detected at the protein level or was also registered at the level of the mRNA for KLC1. A prior report found that KLC1 mRNA levels were unchanged [47]. To address this question, we quantitated the levels of KLC1 mRNA in the same randomly chosen set of AD-DS and C/AD-DS cases used for comparing the levels of KIF5 mRNAs. No change in KLC1 mRNA was found (Supplemental Figure 5). This finding suggests that differences in translation or degradation of KLC1 underlie the reductions seen in AD and AD-DS.

\section{Examining correlations between KLC1, KIF5 members and fl-APP}

Next, we examined possible relationships between the levels of KIF5 levels and KLC1, a topic addressed in the earlier publication that pointed to a positive correlation [48]. Normalizing to $\beta$-actin, we failed to find correlations for KIF5 members and KLC1 in the AD and AD-DS samples; a single positive correlation in the $\mathrm{C} / \mathrm{COMB}$ samples was absent when normalizing with GAPDH (Supplemental Table 7A, B). When we tested for correlations between KLC1 and flhAPP and normalized with $\beta$-actin, we found significant positive correlations for $\mathrm{C} / \mathrm{COMB}$ and for $\mathrm{AD}$, but not for AD-DS (Supplemental Table 7A); when normalizing with 


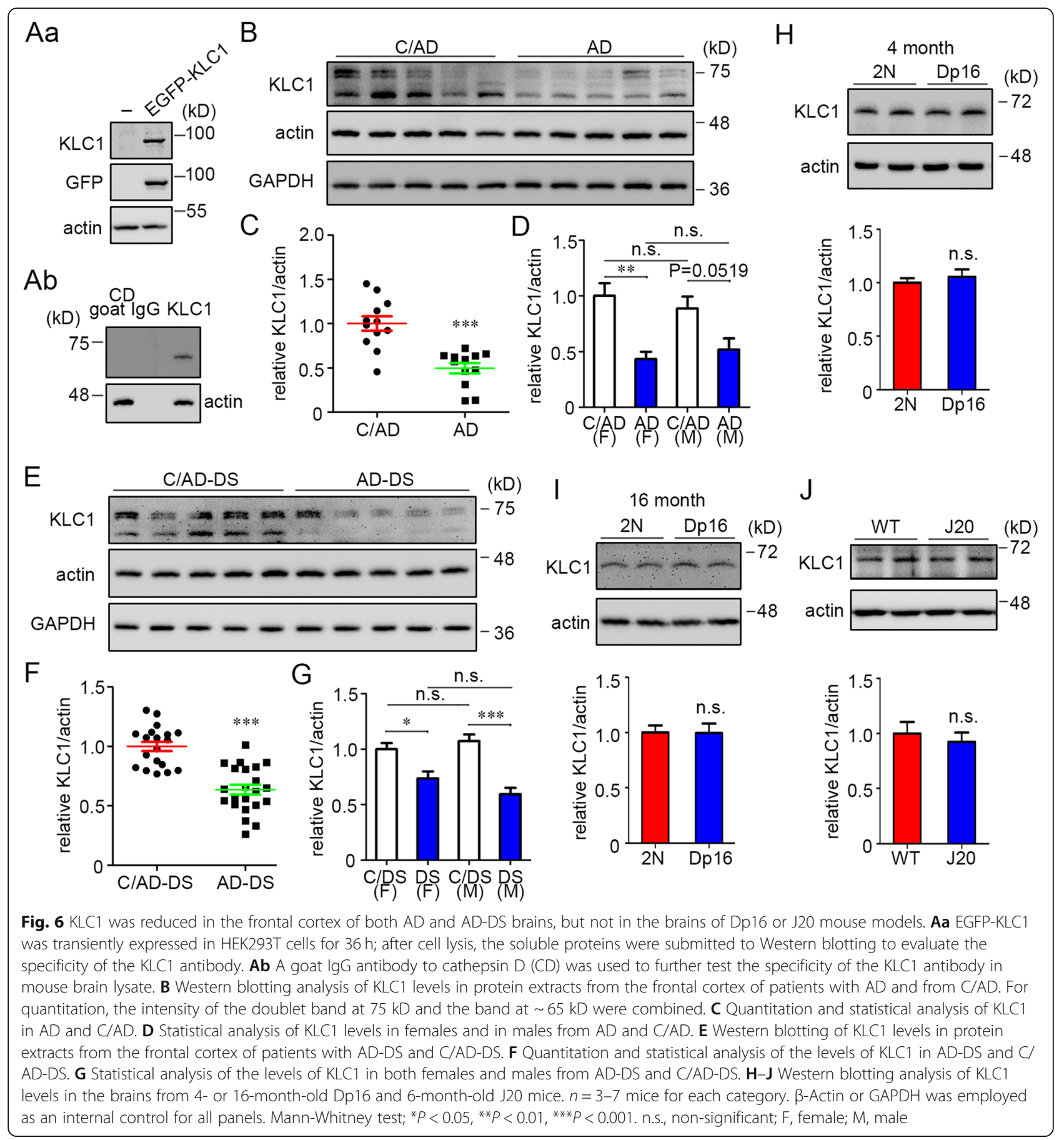

GAPDH, only the correlation in $\mathrm{C} / \mathrm{COMB}$ remained (Supplemental Table 7B). Finally, as for the human samples, while KLC1 was not correlated with KIF5 family members in either $2 \mathrm{~N}$ or Dp16 brains, it was correlated with fl-mAPP in $2 \mathrm{~N}$ brains (Supplemental Table 7A). These findings are evidence against consistent correlations between KLC1 and KIF5 members or between KLC1 and fl-hAPP in the AD and AD-DS brains.

\section{Discussion}

Disruption of axonal transport has been suggested as contributing to the pathogenesis of neurodegenerative disorders including $\mathrm{AD}$ and $\mathrm{DS}[1,17,64,65]$. The essential roles played by axonal transport point to this facet of neuron function as a potential source of vulnerability to degeneration. Many factors can be envisioned to contribute to deficits in axonal transport: abnormal microtubule dynamics/stability, deficits in essential 
cargoes, deficiencies in adaptor proteins that scaffold cargoes for loading onto motor proteins, and abnormalities in the levels/functions of motor proteins and complexes responsible for transporting cargoes to and from cell bodies.

It is interesting that KIF5 family members have been shown to be connected to many neurodegenerative disorders. KIF5A along with other kinesin members including KIF1B and KIF21B were significantly reduced at the mRNA level and KIF5A at the protein level in gray matter of multiple sclerosis (MS) brains [66]. In another study, KIF5A was reduced in MS white matter, and individuals carrying certain MS risk alleles demonstrated decreased levels of KIF5A [67]. Changes in KIF21B have also been reported in MS and AD [68]. In addition to changes in expression of KIF5 proteins, mutations in the KIF5A gene were associated with several neurodegenerative diseases including hereditary spastic paraplegias (SPG10), Charcot-Marie-Tooth type 2 (CMT2), amyotrophic lateral sclerosis-frontotemporal dementia (ALS-FTD), and MS, supporting a significant role for KIF5 family members, including KIF5A, in disorders implicating disrupted axonal transport [69-73].

There is little data for which, if any, proteins that support axonal transport contribute to neuron dysfunction and loss in AD and AD-DS, but recent studies pointed to changes in the levels of motor proteins or adaptor proteins. Thus, changes in both KIF5A and KLC1 in AD have been reported [43, 45-47]. Though changes in either could disrupt anterograde axonal transport, these earlier reports were inconsistent and conflicting [42, 43, $47,48]$.

In this study, we examined the levels of KIF5 family members and KLC1 in both AD and AD-DS brains and normalized to both $\beta$-actin and to GAPDH. No changes were detected in the average level of KIF5 family members in $\mathrm{AD}$ and AD-DS in comparison with controls, nor were there changes in KIF5 members comparing males to females or across the age span in $A D$ or $\mathrm{AD}$-DS. Interestingly, evidence for coordinate regulation of KIF5 family members was discovered in AD, AD-DS, and control sample sets. Positive correlations between KIF5 members and the level of fl-APP were also detected for $\mathrm{AD}-\mathrm{DS}, \mathrm{AD}$, and control samples. Importantly, in contrast to the findings for KIF5, both the $\mathrm{AD}$ and AD-DS frontal cortex samples showed significant reductions in $\mathrm{KLC} 1$ in both males and females, including a subset of samples with a PMI shorter than that shown to be correlated with degradation of KLC1. These findings raise the possibility of reductions in the anterograde transport of selected cargoes in AD and AD-DS and prompt additional studies to test this hypothesis.

Our findings for KIF5 family members in AD are at odds with recently published work [43]. Several possibilities exist to explain the difference in findings. First, while brain region-specific changes of KIF5A may contribute, our studies sampling both frontal and temporal cortex showed no reductions. Thus, our findings are at odds with a previous study that examined KIF5 levels in the temporal cortex [43]. Sample quality is another factor to be considered. We noted significant variability across samples in the levels of KIF5B and KIF5C, especially for KIF5A. As a speculation, differences in the stability of KIF5 proteins in postmortem samples and longer PMIs could contribute to the differences across studies [74]. We employed samples with a far shorter average PMI for both $\mathrm{AD}$ and controls than for earlier studies demonstrating either a decrease in KIF5A [43] or an increase in KIF5A [42] (Supplemental Table 8). Importantly, we were able to show that PMIs as long as 23 $h$ had no obvious effects on the levels of any KIF5 members (Supplemental Table 6). Samples with PMIs as long as $72 \mathrm{~h}$ were examined in earlier reports, possibly contributing to different findings [42, 48]. In contrast to the relative stability of KIF5 members, we found a significant negative correlation between PMI and KLC1 in AD and AD-DS brains but, interestingly, not in control brains. However, we confirmed the significant reduction of KLC1 in both AD and AD-DS samples with PMIs $\leq 6 \mathrm{~h}-$ i.e., under conditions in which there was no significant postmortem degradation of $\mathrm{KLC} 1$ in either AD or AD-DS samples. It is interesting, then, that the stability of KLC1 serves to distinguish control and disease brains. Another important consideration is the method for detecting changes. The use of dot blot technology is inherently less accurate for evaluating protein levels than Western blotting; this source of error is reduced when only a band of the expected molecular weight is quantitated. Finally, sample number is a consideration. While two earlier studies employed a large number of $\mathrm{AD}$ samples [42, 48], far fewer were examined in a study reporting a reduction in KIF5A and KIF5B $(n=4$ for AD) [43] (Supplemental Table 8). We examined $12 \mathrm{AD}, 21 \mathrm{AD}-\mathrm{DS}$, and a total of 21 control samples. We conclude that differences in PMI and in analytical methods, and in one case the number of samples used, best account for the differences in findings between earlier studies and ours.

Using two different loading controls, $\beta$-actin or GAPD $\mathrm{H}$, we observed correlations in the levels of KIF5 family members at the protein level in $\mathrm{AD}, \mathrm{AD}-\mathrm{DS}$, and controls, evidence suggesting co-regulation among the three KIF5 family members. To exclude possible spurious correlations between ratios with a common divisor [75], we then re-examined the positive correlations by determining whether they persisted when one KIF5 member was normalized to $\beta$-actin and the other to GAPDH. Most positive correlations remained (Supplemental Table 9). To supplement these findings, we measured the mRNA levels of KIF5 members in AD-DS and C/AD-DS brains, finding that the levels of individual 
KIF5 members were highly correlated with one another. The mechanism underlying is yet to be defined but suggests regulation at the levels of mRNA. Interestingly, manipulation of any KIF5 member through gene knockout or siRNA-mediated knockdown had no obvious effects on the others [32, 76, 77]. These earlier findings are consistent with our findings that overexpression of each KIF5 member in transfected cell systems did not change the levels of the other members. Further studies will be needed to understand what are apparently different regulatory modes for endogenous and extrinsically induced changes in expression.

Given the increase in APP gene dose and APP and its products in DS, and earlier reports linking APP levels to KIF5A in AD, it was of interest to ask if APP protein levels were correlated with KIF5. Others found that flAPP was negatively correlated with KIF5A levels in AD; however, the significance of this finding was uncertain, especially given that KIF5A levels were not a function of the Braak stage in AD [48]. Nor did the authors find a significant correlation between KIF5A and either soluble or insoluble $A \beta$ species [48], even though another study argued for a role for $\mathrm{A} \beta$ in reducing KIF5A in $\mathrm{AD}$ [43]. Strikingly, we found a positive correlation between flAPP levels and each KIF5 member in AD, AD-DS, and control samples, albeit with differences on the basis of which protein was used to normalize the samples. To test for possible spurious correlations, we re-examined samples showing positive correlations by determining whether they persisted when a KIF5 member was normalized to GAPDH and fl-APP was normalized to $\beta$ actin. Most positive correlations remained (Supplemental Table 9). Whether or not KIF5 levels and fl-APP levels are mechanistically linked is uncertain. APP itself is transported by the KIF5/KLC complex and can be coimmunoprecipitated by antibodies against all the KIF5 family members and KLC1 or KLC2 from mouse brain lysates [78]. Interestingly, compared with KIF5A, the association of KIF5B or KIF5C with APP depends to a greater extent on $\mathrm{KLC} 1$ than $\mathrm{KLC} 2$, reflecting the uniqueness of each KIF5 [78]. As a speculation, it is intriguing to suggest that fl-APP levels positively regulate the levels of KIF5 members. The discrepancies between our findings and others for KIF5 members and fl-APP are subject to some of the same considerations as for KIF5 members alone, as cited above.

KIF5 complexes with KLC subunit to engage in axonal transport [4]. The significance of this interaction is indicated by genetic deletion of KLC which results in early selective axonal transport deficits accompanied by axonopathies with cytoskeletal disorganization and abnormal cargo accumulation [79]. Axonal transport of APP was shown to be mediated by direct binding to KLC1 and APP axonal transport was significantly reduced in a
KLC1 mutant mouse [78], suggesting an essential role for KLC1 in anterograde axonal transport of APP. Regulated movement of APP-containing vesicles has been described. For example, the JNK-interacting protein 1 (JIP1) has been shown to regulate APP axonal transport through binding to KLC1 [80]. Calsyntenin-1, a KLC ligand, has been linked to APP axonal transport and APP processing [81, 82]. Given these findings, the reported downregulation of $\mathrm{KLC1}$ in $\mathrm{AD}$ brains is of considerable interest [45-47]. In our study, there was a significant marked reduction of KLC1 in the frontal cortex of both AD and AD-DS but not the temporal cortex and cerebellum. These data point to another shared element of pathogenesis for $\mathrm{AD}$ and $\mathrm{AD}-\mathrm{DS}$ and to the possibility that reductions in KLC1 are responsible for disrupting the transport of KLC1-mediated movement of cargoes in these regions.

Comparing the findings in human samples with those in the brains of the Dp16 mouse model of DS and the J20 model of AD pointed to both similarities and differences. KIF5 levels were maintained at control levels in both models, and in the Dp16 model, the levels KIF5 family members were positively correlated. However, in contrast to human cases, there was no correlation between fl-APP levels and KIF5 levels in the Dp16 model, pointing to a potentially important difference in the regulation of KIF5 levels in the mouse. A more striking disconnect with human samples was that KLC1 levels were not reduced in either the Dp16 or J20 mouse. Whether subregional analysis would detect the differences in these models will require further study. At present, our findings suggest that models to explore KLC1-mediated changes in anterograde transport in the Dp16 or J20 mouse will require interventions to downregulate KLC1.

\section{Limitations}

The use of postmortem human tissues poses limitations to findings and their interpretation. While there are clear benefits to such use, including the ability to underpin and thereby ground findings to allow for comparisons between model systems and humans, the quality of human postmortem samples is a function of the PMI. Extended PMIs result in degradation of molecules and cells; in the extreme case, the degree of degradation would invalidate findings and conclusions [74]. To address this limitation, we employed samples with a relatively short average PMI. Indeed, on average, it was well within the range reported to preserve the integrity of RNA [74], a species known to be especially susceptible to postmortem degradation. Moreover, we found no evidence of PMI-linked reductions in KIF5 members in control, AD, or AD-DS samples. Also, we note that PMI is not a factor for the mouse samples, which can be 
frozen rapidly, and that the levels of KIF5 family members in mouse brain were also positively correlated with one another, as was seen in human samples. Finally, we observed a significant negative correlation between KLC1 and PMI in AD and AD-DS, but not in control brains, and confirmed the reduction of KLC1 in AD and AD-DS samples with a very short PMI-i.e., using PMIs wherein there were no significant correlations in the levels of KLC1 in either AD or AD-DS.

A second limitation is the extent to which our findings speak to KIF5 and KLC1 levels in all AD-vulnerable human brain regions. We examined the levels in the frontal cortex of human AD and AD-DS samples and the temporal cortex and cerebellum of AD samples. We note that KIF5 family members were preserved in all regions and that KLC1 was reduced only in the frontal cortex. A more complete list of regions bearing $\mathrm{AD}$ pathology will be needed to further explore the existence of regional changes and their possible links to changes in axonal transport.

A third limitation is that while the reduction in KLC1 suggests there may be defects in anterograde transport, direct evidence demonstrating this will be required to prove the point. An important question is what model system would be appropriate for such a study. Because KLC1 was not changed in the mouse models of either $\mathrm{AD}$ or AD-DS, studies in mouse neurons in which KLC1 was knocked down would be needed to recapitulate this change. But it is possible that the cellular environment so created would differ considerably from that in human neurons. Studies in the Dp16 mouse could at least explore the reduction in KLC1 in a genetic environment in which there is increased gene dose for many of the mouse homologs of human genes on chromosome 21 . Moreover, the Dp16 and related models may prove useful in exploring other factors that could impact axonal transport, including those that act through posttranslational modification of KIF5s and KLC1 [45, 83]. Of possibly greater value would be the use of human in vitro models of induced pluripotent stem cell (iPSC)derived control, $\mathrm{AD}$ and $\mathrm{AD}-\mathrm{DS}$ neurons to determine whether or not KLC1 is reduced and, if so, the potential consequences for the transport of known cargoes, such as APP. Indeed, human neurons that model sporadic AD and AD-DS, as well as familial AD (FAD), may provide unique opportunities to determine whether or not axonal transport is compromised.

\section{Conclusion}

In summary, we show that while KIF5 family members were not changed in $\mathrm{AD}$ or $\mathrm{AD}-\mathrm{DS}$, significant reductions were detected in KLC1 in a subset of samples with PMI $(\leq 6 \mathrm{~h})$ thus raising the possibility that disruption of anterograde axonal transport may be discovered for both conditions. Our results thus unveil novel shared molecular features in $\mathrm{AD}$ and $\mathrm{AD}-\mathrm{DS}$ and point to the importance of further studies to explore the significance of changes in the Kinesin-1 complex in the pathogenesis of $\mathrm{AD}$ and $\mathrm{AD}-\mathrm{DS}$.

\section{Abbreviations}

RNAs: Ribonucleic acids; AD: Alzheimer's disease; DS: Down syndrome; ADDS: AD in DS; KIF5: Kinesin family member 5; KLC: Kinesin light chain; APP: Amyloid precursor protein; PD: Parkinson disease; HD: Huntington disease; ALS: Amyotrophic lateral sclerosis; NFTs: Neurofibrillary tangles; HSA21: Human chromosome 21; KHC: Kinesin heavy chain;

mRNA: Messenger ribonucleic acid; fl-APP: Full-length APP; CTF: C-terminal fragment; PMI: Postmortem interval; GAPDH: Glyceraldehyde-3-phosphate dehydrogenase; fl-hAPP: Full-length human APP; fl-mAPP: Full-length mouse APP; OE: Overexpression; KO: Knockout; MS: Multiple sclerosis; CMT2: CharcotMarie-Tooth type 2; ALS-FTD: Amyotrophic lateral sclerosis-frontotemporal dementia; JIP1: JNK-interacting protein 1; FAD: Familial AD; iPSC: Induced pluripotent stem cell

\section{Supplementary Information}

The online version contains supplementary material available at https://doi. org/10.1186/s13195-021-00796-6.

Additional file 1:. Supplementary figures and tables.

\section{Acknowledgements}

We thank the many participants and their family members for participating in the brain donation programs that made this research possible. We are grateful to Banner Sun Health Research Institute, UCI MIND, and NIH NeuroBioBank for providing frozen human brain tissue specimens. We also thank Drs. Johnstone Aaron and Orlangie Natera (Department of Neurosciences, University of California San Diego, USA) for the helpful comments.

\section{Authors' contributions}

X.-Q.C. and W.C.M. designed the research. X.-Q.C. and U.D. performed the experiments. X.-Q.C. analyzed the data. G.P. provided samples. X.-Q.C. and W.C.M. wrote the paper. All authors reviewed the paper. The authors read and approved the final manuscript.

\section{Funding}

This research was supported by grants from the DH Chen Foundation (R86U55A, WCM) and NIH R01AG061151 and R01AG055523 (WCM).

Availability of data and materials

All data generated or analyzed during this study are included in this article.

\section{Declarations}

Ethics approval and consent to participate

All the procedures related to human samples were carried out under a protocol reviewed and approved by the human subjects review board at UCSD (IRB \#: 180620). All the animal studies were performed strictly according to the recommendations in the Guide for the Care and Use of Laboratory Animals of the National Institutes of Health. All experiments involving the use of animals have been approved by the University of California San Diego Institutional Animal Care and Use Committee (Protocol \#: S09315, S02216M).

Consent for publication

Not applicable.

Competing interests

The authors declare that they have no competing interests. 


\section{Received: 24 November 2020 Accepted: 22 February 2021} Published online: 10 March 2021

\section{References}

1. Guo W, Stoklund Dittlau K, Van Den Bosch L. Axonal transport defects and neurodegeneration: molecular mechanisms and therapeutic implications. Semin Cell Dev Biol. 2020;99:133-50.

2. Sleigh JN, Rossor AM, Fellows AD, Tosolini AP, Schiavo G. Axonal transport and neurological disease. Nat Rev Neurol. 2019;15(12):691-703.

3. Hirokawa N, Noda Y, Tanaka Y, Niwa S. Kinesin superfamily motor proteins and intracellular transport. Nat Rev Mol Cell Biol. 2009;10(10):682-96.

4. Hirokawa N, Niwa S, Tanaka Y. Molecular motors in neurons: transport mechanisms and roles in brain function, development, and disease. Neuron. 2010;68(4):610-38

5. Bosco DA, Morfini G, Karabacak NM, Song Y, Gros-Louis F, Pasinelli P Goolsby H, Fontaine BA, Lemay N, McKenna-Yasek D, et al. Wild-type and mutant SOD1 share an aberrant conformation and a common pathogenic pathway in ALS. Nat Neurosci. 2010;13(11):1396-403.

6. Morfini GA, You YM, Pollema SL, Kaminska A, Liu K, Yoshioka K, Bjorkblom B, Coffey ET, Bagnato C, Han D, et al. Pathogenic huntingtin inhibits fast axonal transport by activating JNK3 and phosphorylating kinesin. Nat Neurosci. 2009;12(7):864-71.

7. Pigino G, Morfini G, Atagi Y, Deshpande A, Yu C, Jungbauer L, LaDu M, Busciglio J, Brady S. Disruption of fast axonal transport is a pathogenic mechanism for intraneuronal amyloid beta. Proc Natl Acad Sci U S A. 2009; 106(14):5907-12

8. Chen XQ, Salehi A, Pearn ML, Overk C, Nguyen PD, Kleschevnikov AM, Maccecchini M, Mobley WC. Targeting increased levels of APP in Down syndrome: Posiphen-mediated reductions in APP and its products reverse endosomal phenotypes in the Ts65Dn mouse model. Alzheimers Dement. 2021;17(2):271-92.

9. Mo Z, Zhao X, Liu H, Hu Q, Chen XQ, Pham J, Wei N, Liu Z, Zhou J, Burgess RW, et al. Aberrant GlyRS-HDAC6 interaction linked to axonal transport deficits in Charcot-Marie-Tooth neuropathy. Nat Commun. 2018;9(1):1007.

10. Zhao X, Chen XQ, Han E, Hu Y, Paik P, Ding Z, Overman J, Lau AL, Shahmoradian SH, Chiu W, et al. TRiC subunits enhance BDNF axonal transport and rescue striatal atrophy in Huntington's disease. Proc Natl Acad Sci U S A. 2016;113(38):E5655-64.

11. Xu W, Weissmiller AM, White JA 2nd, Fang F, Wang X, Wu Y, Pearn ML, Zhao X, Sawa M, Chen S, et al. Amyloid precursor protein-mediated endocytic pathway disruption induces axonal dysfunction and neurodegeneration. J Clin Invest. 2016;126(5):1815-33.

12. Tammineni $P, Y e X$, Feng $T$, Aikal D, Cai $Q$. Impaired retrograde transport of axonal autophagosomes contributes to autophagic stress in Alzheimer's disease neurons. eLife. 2017;6:e21776.

13. Didonna A, Opal P. The promise and perils of HDAC inhibitors in neurodegeneration. Ann Clin Transl Neurol. 2015;2(1):79-101.

14. Plassman $\mathrm{BL}$, Langa KM, Fisher GG, Heeringa SG, Weir DR, Ofstedal MB, Burke JR, Hurd MD, Potter GG, Rodgers WL, et al. Prevalence of dementia in the United States: the aging, demographics, and memory study. Neuroepidemiology. 2007;29(1-2):125-32.

15. Scheltens P, Blennow K, Breteler MM, de Strooper B, Frisoni GB, Salloway S, Van der Flier WM. Alzheimer's disease. Lancet. 2016;388(10043):505-17.

16. Davis M, T OC, Johnson S, cline S, Merikle E, Martenyi F, Simpson K: Estimating Alzheimer's disease progression rates from normal cognition through mild cognitive impairment and stages of dementia. Curr Alzheimer Res 2018, 15(8):777-788.

17. Chen XQ, Mobley WC. Alzheimer disease pathogenesis: insights from molecular and cellular biology studies of oligomeric Abeta and tau species. Front Neurosci. 2019;13:659.

18. Ballard C, Mobley W, Hardy J, Williams G, Corbett A. Dementia in Down's syndrome. The Lancet Neurol. 2016;15(6):622-36.

19. Wiseman FK, Al-Janabi T, Hardy J, Karmiloff-Smith A, Nizetic D, Tybulewicz VL, Fisher EM, Strydom A. A genetic cause of Alzheimer disease: mechanistic insights from Down syndrome. Nat Rev. 2015;16(9):564-74.

20. Megarbane A, Ravel A, Mircher C, Sturtz F, Grattau Y, Rethore MO, Delabar JM, Mobley WC. The 50th anniversary of the discovery of trisomy 21: the past, present, and future of research and treatment of Down syndrome. Genet Med. 2009;11(9):611-6.

21. Korbel JO, Tirosh-Wagner T, Urban AE, Chen XN, Kasowski M, Dai L, Grubert F, Erdman C, Gao MC, Lange K, et al. The genetic architecture of Down syndrome phenotypes revealed by high-resolution analysis of human segmental trisomies. Proc Natl Acad Sci U S A. 2009;106(29):12031-6.

22. Doran E, Keator D, Head E, Phelan MJ, Kim R, Totoiu M, Barrio JR, Small GW, Potkin SG, Lott IT. Down syndrome, partial trisomy 21, and absence of Alzheimer's disease: the role of APP. J Alzheimers Dis. 2017;56(2):459-70.

23. Prasher VP, Farrer MJ, Kessling AM, Fisher EM, West RJ, Barber PC, Butler AC. Molecular mapping of Alzheimer-type dementia in Down's syndrome. Ann Neurol. 1998:43(3):380-3.

24. Swerdlow RH. Mitochondria and mitochondrial cascades in Alzheimer's disease. J Alzheimers Dis. 2018;62(3):1403-16.

25. Gowrishankar S, Wu Y, Ferguson SM. Impaired JIP3-dependent axonal lysosome transport promotes amyloid plaque pathology. J Cell Biol. 2017; 216(10):3291-305

26. Chen $X Q$, Mobley WC. Exploring the pathogenesis of Alzheimer disease in basal forebrain cholinergic neurons: converging insights from alternative hypotheses. Front Neurosci. 2019;13:446.

27. Chen XQ, Sawa M, Mobley WC. Dysregulation of neurotrophin signaling in the pathogenesis of Alzheimer disease and of Alzheimer disease in Down syndrome. Free Radic Biol Med. 2018:114:52-61.

28. Kamal A, Almenar-Queralt A, LeBlanc JF, Roberts EA, Goldstein LS. Kinesinmediated axonal transport of a membrane compartment containing betasecretase and presenilin-1 requires APP. Nature. 2001;414(6864):643-8.

29. Tanaka Y, Kanai Y, Okada Y, Nonaka S, Takeda S, Harada A, Hirokawa N. Targeted disruption of mouse conventional kinesin heavy chain, kif5B, results in abnormal perinuclear clustering of mitochondria. Cell. 1998;93(7): 1147-58.

30. Dictenberg JB, Swanger SA, Antar LN, Singer RH, Bassell GJ. A direct role for FMRP in activity-dependent dendritic mRNA transport links filopodial-spine morphogenesis to fragile X syndrome. Dev Cell. 2008;14(6):926-39.

31. Colin E, Zala D, Liot G, Rangone H, Borrell-Pages M, Li XJ, Saudou F, Humbert S. Huntingtin phosphorylation acts as a molecular switch for anterograde/retrograde transport in neurons. EMBO J. 2008;27(15):2124-34.

32. Kanai Y, Okada Y, Tanaka Y, Harada A, Terada S, Hirokawa N. KIF5C, a novel neuronal kinesin enriched in motor neurons. J Neurosci. 2000;20(17): 6374-84.

33. Rahman A, Kamal A, Roberts EA, Goldstein LS. Defective kinesin heavy chain behavior in mouse kinesin light chain mutants. J Cell Biol. 1999;146(6):1277-88.

34. Zhang YW, Thompson $\mathrm{R}$, Zhang $\mathrm{H}, \mathrm{Xu} \mathrm{H}$. APP processing in Alzheimer's disease. Mol Brain. 2011;4:3.

35. Das U, Wang L, Ganguly A, Saikia JM, Wagner SL, Koo EH, Roy S. Visualizing APP and BACE-1 approximation in neurons yields insight into the amyloidogenic pathway. Nat Neurosci. 2016;19(1):55-64.

36. Niederst ED, Reyna SM, Goldstein LS. Axonal amyloid precursor protein and its fragments undergo somatodendritic endocytosis and processing. Mol Biol Cell. 2015:26(2):205-17.

37. Salehi A, Delcroix JD, Belichenko PV, Zhan K, Wu C, Valletta JS, TakimotoKimura R, Kleschevnikov AM, Sambamurti K, Chung PP, et al. Increased App expression in a mouse model of Down's syndrome disrupts NGF transport and causes cholinergic neuron degeneration. Neuron. 2006:51(1):29-42.

38. Rodrigues EM, Weissmiller AM, Goldstein LS. Enhanced beta-secretase processing alters APP axonal transport and leads to axonal defects. Hum Mol Genet. 2012;21(21):4587-601

39. Decker H, Lo KY, Unger SM, Ferreira ST, Silverman MA. Amyloid-beta peptide oligomers disrupt axonal transport through an NMDA receptordependent mechanism that is mediated by glycogen synthase kinase 3 beta in primary cultured hippocampal neurons. J Neurosci. 2010;30(27):9166-71.

40. Calkins MJ, Reddy PH. Amyloid beta impairs mitochondrial anterograde transport and degenerates synapses in Alzheimer's disease neurons. Biochim Biophys Acta. 2011;1812(4):507-13.

41. Kim S, Sato Y, Mohan PS, Peterhoff C, Pensalfini A, Rigoglioso A, Jiang Y, Nixon RA. Evidence that the rab5 effector APPL1 mediates APP-betaCTFinduced dysfunction of endosomes in Down syndrome and Alzheimer's disease. Mol Psychiatry. 2016;21(5):707-16

42. Hares K, Miners JS, Cook AJ, Rice C, Scolding N, Love S, Wilkins A. Overexpression of Kinesin superfamily motor proteins in Alzheimer's disease. J Alzheimers Dis. 2017:60(4):1511-24.

43. Wang Q, Tian J, Chen H, Du H, Guo L. Amyloid beta-mediated KIF5A deficiency disrupts anterograde axonal mitochondrial movement. Neurobiol Dis. 2019;127:410-8.

44. Sepulveda-Falla D, Barrera-Ocampo A, Hagel C, Korwitz A, Vinueza-Veloz MF, Zhou K, Schonewille M, Zhou H, Velazquez-Perez L, Rodriguez-Labrada R, 
et al. Familial Alzheimer's disease-associated presenilin-1 alters cerebellar activity and calcium homeostasis. J Clin Invest. 2014;124(4):1552-67.

45. Morotz GM, Glennon EB, Greig J, Lau DHW, Bhembre N, Mattedi F, Muschalik N, Noble W, Vagnoni A, Miller CCJ. Kinesin light chain-1 serine460 phosphorylation is altered in Alzheimer's disease and regulates axonal transport and processing of the amyloid precursor protein. Acta Neuropathol Commun. 2019;7(1):200.

46. Sherman MA, LaCroix M, Amar F, Larson ME, Forster C, Aguzzi A, Bennett DA, Ramsden M, Lesne SE. Soluble conformers of Abeta and tau alter selective proteins governing axonal transport. J Neurosci. 2016;36(37): 9647-58.

47. Morel M, Heraud C, Nicaise C, Suain V, Brion JP. Levels of kinesin light chain and dynein intermediate chain are reduced in the frontal cortex in Alzheimer's disease: implications for axoplasmic transport. Acta Neuropathol. 2012;123(1):71-84.

48. Hares K, Miners S, Scolding N, Love S, Wilkins A. KIF5A and KLC1 expression in Alzheimer's disease: relationship and genetic influences [version 2; peer review: 2 approved, 1 approved with reservations]. AMRC Open Res. 2019;1: 1 https://doi.org/10.12688/amrcopenres.12861.12682.

49. Yu T, Li Z, Jia Z, Clapcote SJ, Liu C, Li S, Asrar S, Pao A, Chen R, Fan N, et al. A mouse model of Down syndrome trisomic for all human chromosome 21 syntenic regions. Hum Mol Genet. 2010;19(14):2780-91.

50. Goodliffe JW, Olmos-Serrano JL, Aziz NM, Pennings JL, Guedj F, Bianchi DW, Haydar TF. Absence of prenatal forebrain defects in the Dp (16)1Yey/+ mouse model of Down syndrome. J Neurosci. 2016;36(10):2926-44.

51. Gardiner KJ. Pharmacological approaches to improving cognitive function in Down syndrome: current status and considerations. Drug Des Dev Ther. 2015;9:103-25.

52. Zheng $H$, Jiang $M$, Trumbauer ME, Sirinathsinghji DJ, Hopkins $R$, Smith DW Heavens RP, Dawson GR, Boyce S, Conner MW et al: $\beta$-Amyloid precursor protein-deficient mice show reactive gliosis and decreased locomotor activity. Cell 1995, 81(4):525-531.

53. Chen XQ, Zhu JX, Wang Y, Zhang X, Bao L. CaMKllalpha and caveolin-1 cooperate to drive ATP-induced membrane delivery of the P2X3 receptor. J Mol Cell Biol. 2014;6(2):140-53.

54. Spandidos A, Wang X, Wang H, Seed B. PrimerBank: a resource of human and mouse PCR primer pairs for gene expression detection and quantification. Nucleic Acids Res. 2010;38(Database issue):D792-9.

55. Rafii MS, Kleschevnikov AM, Sawa M, Mobley WC. Down syndrome. Handb Clin Neurol. 2019;167:321-36.

56. Iulita MF, Do Carmo S, Ower AK, Fortress AM, Flores Aguilar L, Hanna M, Wisniewski T, Granholm AC, Buhusi M, Busciglio J, et al. Nerve growth factor metabolic dysfunction in Down's syndrome brains. Brain. 2014;137(Pt 3): 860-72.

57. Salehi A, Faizi M, Colas D, Valletta J, Laguna J, Takimoto-Kimura R, Kleschevnikov A, Wagner SL, Aisen P, Shamloo M, et al. Restoration of norepinephrine-modulated contextual memory in a mouse model of Down syndrome. Sci Transl Med. 2009;1(7):7ra17.

58. Yu T, Liu C, Belichenko P, Clapcote SJ, Li S, Pao A, Kleschevnikov A, Bechard AR, Asrar S, Chen R, et al. Effects of individual segmental trisomies of human chromosome 21 syntenic regions on hippocampal long-term potentiation and cognitive behaviors in mice. Brain Res. 2010;1366:162-71.

59. Mucke L, Masliah E, Yu GQ, Mallory M, Rockenstein EM, Tatsuno G, Hu K Kholodenko D, Johnson-Wood K, McConlogue L. High-level neuronal expression of abeta 1-42 in wild-type human amyloid protein precursor transgenic mice: synaptotoxicity without plaque formation. J Neurosci. 2000; 20(11):4050-8

60. Saganich MJ, Schroeder BE, Galvan V, Bredesen DE, Koo EH, Heinemann SF. Deficits in synaptic transmission and learning in amyloid precursor protein (APP) transgenic mice require C-terminal cleavage of APP. J Neurosci. 2006; 26(52):13428-36.

61. Wright AL, Zinn R, Hohensinn B, Konen LM, Beynon SB, Tan RP, Clark IA, Abdipranoto A, Vissel B. Neuroinflammation and neuronal loss precede Abeta plaque deposition in the hAPP-J20 mouse model of Alzheimer's disease. PLoS One. 2013;8(4):e59586.

62. Hong S, Beja-Glasser VF, Nfonoyim BM, Frouin A, Li S, Ramakrishnan S, Merry KM, Shi Q, Rosenthal A, Barres BA, et al. Complement and microglia mediate early synapse loss in Alzheimer mouse models. Science (New York, NY). 2016;352(6286):712-6.

63. Gyoeva FK, Bybikova EM, Minin AA. An isoform of kinesin light chain specific for the Golgi complex. J Cell Sci. 2000;113(Pt 11):2047-54.
64. Millecamps S, Julien JP. Axonal transport deficits and neurodegenerative diseases. Nat Rev. 2013;14(3):161-76.

65. De Vos KJ, Grierson AJ, Ackerley S, Miller CC. Role of axonal transport in neurodegenerative diseases. Annu Rev Neurosci. 2008;31:151-73.

66. Hares K, Kemp K, Rice C, Gray E, Scolding N, Wilkins A. Reduced axonal motor protein expression in non-lesional grey matter in multiple sclerosis. Mult Scler. 2014;20(7):812-21.

67. Hares K, Redondo J, Kemp K, Rice C, Scolding N, Wilkins A. Axonal motor protein KIF5A and associated cargo deficits in multiple sclerosis lesional and normal-appearing white matter. Neuropathol Appl Neurobiol. 2017;43(3): 227-41.

68. Kreft KL, van Meurs M, Wierenga-Wolf AF, Melief MJ, van Strien ME, Hol EM, Oostra BA, Laman JD, Hintzen RQ. Abundant kif21b is associated with accelerated progression in neurodegenerative diseases. Acta Neuropathol Commun. 2014:2:144.

69. Alcina A, Vandenbroeck K, Otaegui D, Saiz A, Gonzalez JR, Fernandez O, Cavanillas ML, Cenit MC, Arroyo R, Alloza I, et al. The autoimmune diseaseassociated KIF5A, CD226 and SH2B3 gene variants confer susceptibility for multiple sclerosis. Genes Immun. 2010;11(5):439-45.

70. Saez-Atienzar S, Dalgard CL, Ding J, Chio A, Alba C, Hupalo DN, Wilkerson $M D$, Bowser R, Pioro EP, Bedlack R, et al. Identification of a pathogenic intronic KIF5A mutation in an ALS-FTD kindred. Neurology. 2020;95(22): 1015-8.

71. Crimella C, Baschirotto C, Arnoldi A, Tonelli A, Tenderini E, Airoldi G, Martinuzzi A, Trabacca A, Losito L, Scarlato M, et al. Mutations in the motor and stalk domains of KIF5A in spastic paraplegia type 10 and in axonal Charcot-Marie-Tooth type 2. Clin Genet. 2012;82(2):157-64.

72. Nicolas A, Kenna KP, Renton AE, Ticozzi N, Faghri F, Chia R, Dominov JA, Kenna BJ, Nalls MA, Keagle P, et al. Genome-wide analyses identify KIF5A as a novel ALS gene. Neuron. 2018;97(6):1268-83 e1266.

73. Reid E, Kloos M, Ashley-Koch A, Hughes L, Bevan S, Svenson IK, Graham FL, Gaskell PC, Dearlove A, Pericak-Vance MA, et al. A kinesin heavy chain (KIF5A) mutation in hereditary spastic paraplegia (SPG10). Am J Hum Genet. 2002;71(5):1189-94.

74. Stan AD, Ghose S, Gao XM, Roberts RC, Lewis-Amezcua K, Hatanpaa KJ, Tamminga CA. Human postmortem tissue: what quality markers matter? Brain Res. 2006;1123(1):1-11.

75. Kim JH. Spurious correlation between ratios with a common divisor. Stat Probabil Lett. 1999:44(4):383-6.

76. Zhao J, Fok AHK, Fan R, Kwan PY, Chan HL, Lo LH, Chan YS, Yung WH, Huang J, Lai CSW, et al. Specific depletion of the motor protein KIF5B leads to deficits in dendritic transport, synaptic plasticity and memory. eLife. 2020; 9:e53456.

77. Karle KN, Mockel D, Reid E, Schols L. Axonal transport deficit in a KIF5A( -/- ) mouse model. Neurogenetics. 2012;13(2):169-79.

78. Kamal A, Stokin GB, Yang Z, Xia CH, Goldstein LS. Axonal transport of amyloid precursor protein is mediated by direct binding to the kinesin light chain subunit of kinesin-I. Neuron. 2000;28(2):449-59.

79. Falzone TL, Stokin GB, Lillo C, Rodrigues EM, Westerman EL, Williams DS, Goldstein LS. Axonal stress kinase activation and tau misbehavior induced by kinesin-1 transport defects. J Neurosci. 2009;29(18):5758-67.

80. Verhey KJ, Meyer D, Deehan R, Blenis J, Schnapp BJ, Rapoport TA, Margolis B. Cargo of kinesin identified as JIP scaffolding proteins and associated signaling molecules. J Cell Biol. 2001;152(5):959-70.

81. Steuble M, Diep TM, Schatzle P, Ludwig A, Tagaya M, Kunz B, Sonderegger P. Calsyntenin-1 shelters APP from proteolytic processing during anterograde axonal transport. Biol Open. 2012;1(8):761-74.

82. Vagnoni A, Perkinton MS, Gray EH, Francis PT, Noble W, Miller CC. Calsyntenin-1 mediates axonal transport of the amyloid precursor protein and regulates Abeta production. Hum Mol Genet. 2012;21(13):2845-54.

83. Padzik A, Deshpande $P$, Hollos $P$, Franker M, Rannikko EH, Cai D, Prus $P$, Magard M, Westerlund N, Verhey KJ, et al. KIF5C S176 phosphorylation regulates microtubule binding and transport efficiency in mammalian neurons. Front Cell Neurosci. 2016;10:57.

\section{Publisher's Note}

Springer Nature remains neutral with regard to jurisdictional claims in published maps and institutional affiliations. 